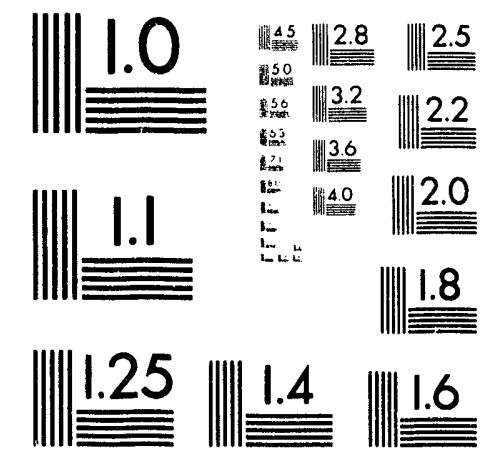



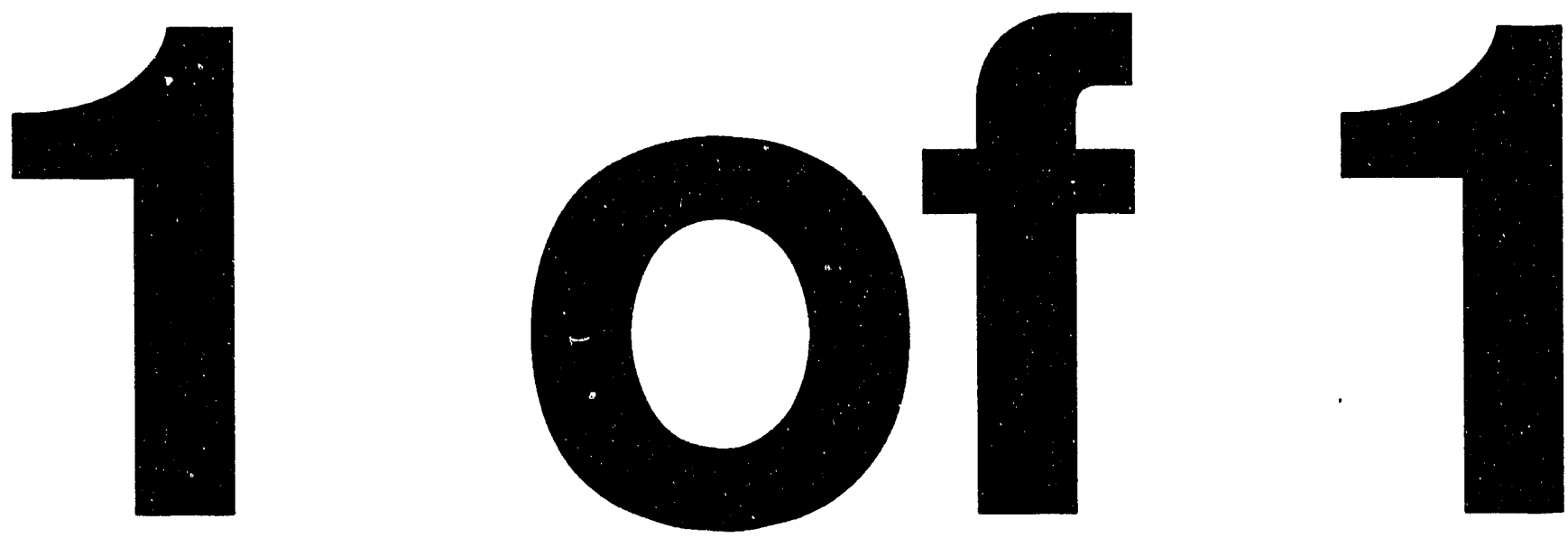
SANDIA REPORT

SAND92- $1832 \cdot U C-704$

Unlimited Re,ease

Printed July 1993
7613 Document Processing for DOE/OSTI (2)

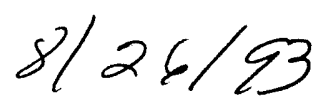

\section{Shock Compression Properties of Silicon Carbide}

D. E. Grady, M. E. Kipp

Prepared by

Sandia National Laboratories

Albuquerque, New Mexico 37185 and Livermore, California 94550

for the United States Department of Energy

under Contract DE-AC04-76DP00789 
Issued by Sandia National Laboratories, operated for the United States Department of Energy by Sandia Corporation.

NOTICE: This report was prepared as an account of work sponsored by an agency of the United States Government. Neither the United States Government nor any agency thereof, nor any of their employees, nor any of their contractors, subcontractors, or their employees, makes any warranty, express or implied, or assumes any legal liability or responsibility for the accuracy, completeness, or usefulness of any information, apparatus, product, or process disclosed, or represents that its use would not infringe privately owned rights. Reference herein to any specific commercial product, process, or service by trade name, trademark, manufacturer, or otherwise, does not necessarily constitute or imply its endorsement, recommendation, or favoring by the United States Government, any agency thereof or any of their contractors or subcontractors. The views and opinions expressed herein do not necessarily state or reflect those of the United States Government, any agency thereof or any of their contractors.

Printed in the United States of America. This report has been reproduced directly from the best available copy.

Available to DOE and DOE contractors from

Office of Scientific and Technical Information

PO Box 62

Oak Ridge, TN 37831

Prices available from (615) 576-8401, FTS 626-8401

Available to the public from

National Technical Information Service

US Department of Commerce

5285 Port Royal Rd

Springfield, VA 22161

NTIS price codes

Printed copy: A03

Microfiche copy: A01 


\title{
Shock Compression Properties of Silicon Carbide
}

\author{
D. E. Grady \\ Experimental Impact Physics Department 1433 \\ and \\ M. E. Kipp \\ Computational Physics \& Mechanics Department 1432 \\ Sandia National Laboratories \\ Albuquerque, NM 87185
}

\begin{abstract}
An investigation of the shock compression and release properties of silicon carbide ceramic has been performed. A series of planar impact experiments has been completed in which stationary target discs of ceramic were struck by plates of either similar ceramic or other appropriate material at velocities up to $2.2 \mathrm{~km} / \mathrm{s}$ with a propellant gun facility. The particle velocity history at the interface between the back of the target ceramic and a lithium-fluoride window material was measured with laser velocity interferometry (VISAR). Impact stresses achieved in these experiments range between about 10 and $50 \mathrm{GPa}$. $\mathrm{Nu}$ merical solutions and analytic methods were used to determine the dynamic compression and release stress-strain behavior of the ceramic. Further analysis of the data was performed to determine dynamic strength and compressibility properties of silicon carbide.
\end{abstract}


Shock Compression Properties of Silicon Carbide

(Intentionally Left Blank) 


\section{Contents}

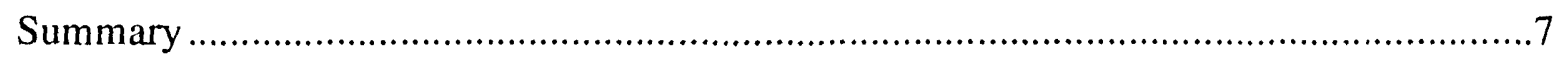

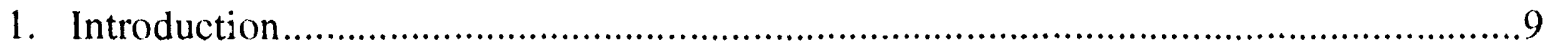

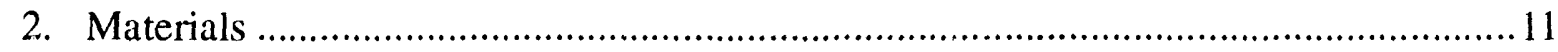

3. Experimental Method................................................................................13

4. Hugoniot Properties .........................................................................................17

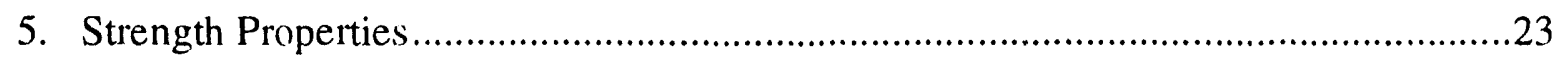

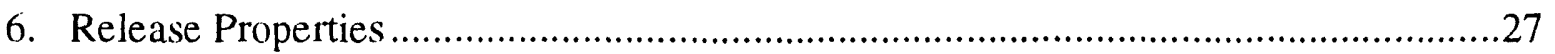

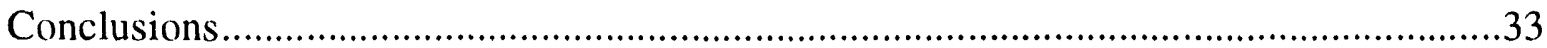

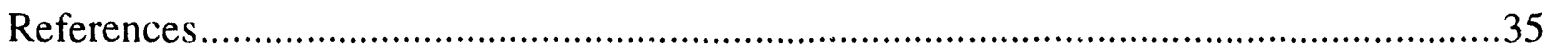

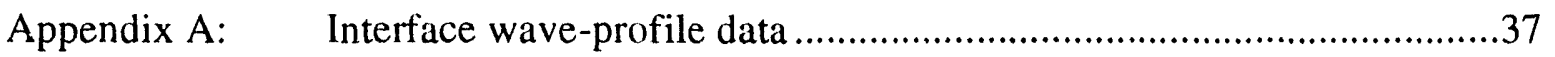

\section{Figures}

1 Back-scatter electron-probe microanalysis (EPMA) photograph of silicon carbide test material.

2 Experimental configuration for shock and release experiments on

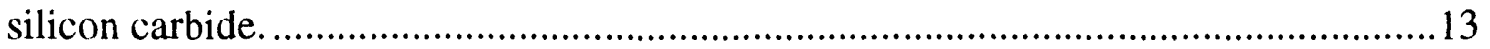

3 Silicon carbide interface velocity profile for Test CE-5. ..........................................15

4 Hugoniot states and dynamic stress-volume paths calculated from wave profile data.

5 Comparison of VISAR wave profile for test CE-31 and Wondy wavecode solution with strain-hardening elastic-plastic model for silicon carbide.

6 Comparison of VISAR wave profile for test CE-32 and SWAP wave-

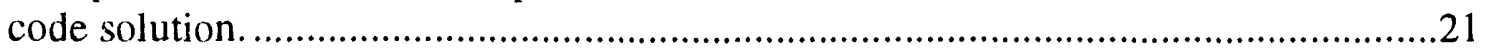

7 Strength properties of an elastic-plastic material.....................................................24

8 Shear stress at the Hugoniot state inferred from Hugoniot and calculated hydrodynamic curve.

9 Initial release velocity and longitudinal modulus at the Hugoniot state. Ultrasonic data correspond to points at initial density of $3177 \mathrm{~kg} / \mathrm{m}^{3}$.

10 Stress derivative of the release moduli for silicon carbide from initial dispersion of unloading wave. 
Shock Compression Properties of Silicon Carbide

11 Multiple shock compression and release experiment and calculation in silicon carbide.

\section{Tables}

1 Experimental conditions for silicon carbide impact tests .................................... 15

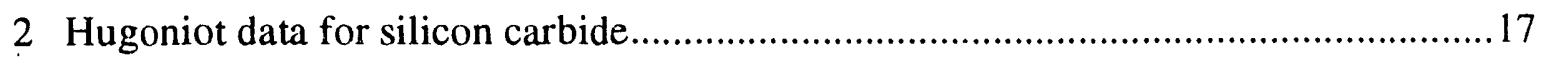

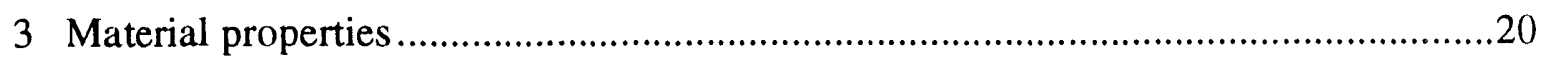

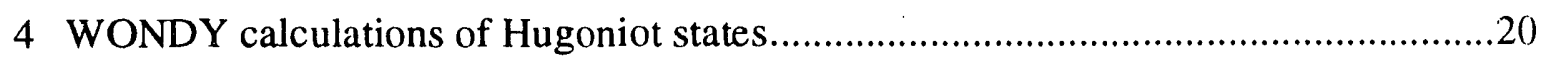




\section{Summary}

The dynamic high-pressure equation-of-state and strength properties of a near theoretical density silicon-carbide ceramic were investigated through controlled planar impact and release-wave experiments. Four planar impact experiments have been completed in which stationary target discs of ceramic were struck by plates of either similar ceramic or tantalum launched at velocities up to $2.1 \mathrm{~km} / \mathrm{s}$ with a propellant gun facility. One further impact experiment was performed in which a layered-impactor configuration led to multiple compression and release of the silicon-carbide sample. Impact stresses achieved in these experiments ranged between about 10 and $50 \mathrm{GPa}$. High-resolution velocity interferometer diagnostics were used to measure time-resolved transmitted particle-velocity profiles. Dynamic material properties were determined through analytic and computational evaluation of the wave profile data.

The Hugoniot of silicon carbide was determined up to an impact stress of $50 \mathrm{GPa}$. The measured Hugoniot elastic limit for this ceramic was $15.3 \pm 0.4 \mathrm{GPa}$. Positive ramping of the wave behind the elastic precursor indicated increasing pressure or inelastic strain hardening with increasing deformation. A dynamic hardening behavior is also supported by increased shear strength at the Hugoniot state calculated from the difference between the dynamic uniaxial strain and hydrodynamic stress states. Analysis of elastic compressibility properties at the Hugoniot states from the release-wave data also gave results consistent with a hardening elastic-plastic behavior in silicon carbide ceramic. No clear indication of a pressure-induced phase transition in silicon carbide below $50 \mathrm{GPa}$ was provided by the wave-profile data. A spall strength of approximately $0.4 \mathrm{GPa}$ was determined from one experiment in which the peak stress state was about $75 \%$ of the Hugoniot elastic limit. Computational simulations of measured wave profiles in silicon carbide, including multiple shock and release, are adequately described with an elastic-plastic work-hardening model. 
(Intentionally Left Blank) 


\section{Introduction}

The present report documents recent shock compression and release data obtained on near theoretical density monolithic $\alpha$-silicon carbide ceramic. The results are part of a broader study of the dynamic strength and equation-of-state properties of a range of high-strength ceramics. Earlier data and analysis are presented in Kipp and Grady (1989) and Grady (1991).

Little previous shock-wave data exists for silicon carbide. The seminal study on this material was performed by Gust, et al. (1973) more than two decades ago. In that study, shock waves in silicon carbide induced by explosive-driven flyer plates were diagnosed by monitoring free-surface displacement using inclined-mirror streak-photography techniques. A Hugoniot elastic limit of about $8 \mathrm{GPa}$ was determined in that work. Hugoniot data were acquired up to a maximum shock pressure of about $100 \mathrm{GPa}$. A shock-induced phase transformation at a pressure of about $24 \mathrm{GPa}$ was inferred from the data by the authors. They suggested that this transition might well be related to the known transformation in silicon.

Recently, Aleksandrov et al. (1990) have performed static high-pressure studies on silicon carbide to nearly $50 \mathrm{GPa}$. They provided initial bulk modulus and pressure derivative data. Volume dependence of the Gruneisen parameter was also established. These authors also suggested that the high pressure properties of silicon carbide are similar to those of silicon. A pressure-induced phase transformation in silicon carbide was not mentioned in the study of Aleksandrov, et al. (1990). Bassett and Weathers (see Holmquist (1991)) have also reported static compressibility data for silicon carbide to nearly $100 \mathrm{GPa}$ using diamond anvil technology.

In the present study controlled impact shock- and release-wave experiments have been performed on silicon carbide. In one test partial release followed by shock recompression and release was accomplished in the silicon carbide sample. Peak stress achieved in the highest amplitude experiments was nearly $50 \mathrm{GPa}$. The lowest amplitude experiment achieved a peak stress below the Hugoniot elastic limit of silicon carbide. Hugoniot, equation-of-state, and dynamic-strength properties were determined for silicon carbide through both analytical and computational analysis of the data. A spall strength for silicon carbide ceramic was also determined from the lowest amplitude experiment. 
Shock Compression Properties of Silicon Carbide

(Intentionally Left Blank) 


\section{Materials}

The silicon carbide tested in the current study was produced by Eagle-Picher Industries. Crystal structure of the starting material was hexagonal (alpha). The initial density and ultrasonic properties were also measured for the present material. They are: initial density = $3177 \mathrm{~kg} / \mathrm{m}^{3}$, longitudinal velocity $=12.06 \mathrm{~km} / \mathrm{s}$, and shear velocity $=7.67 \mathrm{~km} / \mathrm{s}$. Associated elastic properties derived from these velocities are a Poisson's ratio of $v=0.16$ and $C_{o}=8.19$. Electron probe microanalysis (EPMA) revealed inclusions principally of tungsten and tungsten carbide. Minor amounts of molybdenum, chromium and titanium were also present. An equiaxial grain structure with nominal grain size of a yout $10 \mu \mathrm{m}$ was determined. Porosity (about 1\%) in the form of near-spherical cavities un grain boundaries was also observed. Microstructure of the starting material was adequately revealed by the back scatter EPMA image shown in Figure 1.

The lithium fluoride used as the laser window material in the present impact experiments was optically clear $[100]$ oriented single crystals. Closed cell polyurethane foam of nominally 20 and 40 pounds per cubic foot $\left(320\right.$ and $\left.640 \mathrm{~kg} / \mathrm{m}^{3}\right)$ provided backing material for the impactor plate. Three nines pure commercial tantalum was used as impactor material in the highest shock pressure experiment.

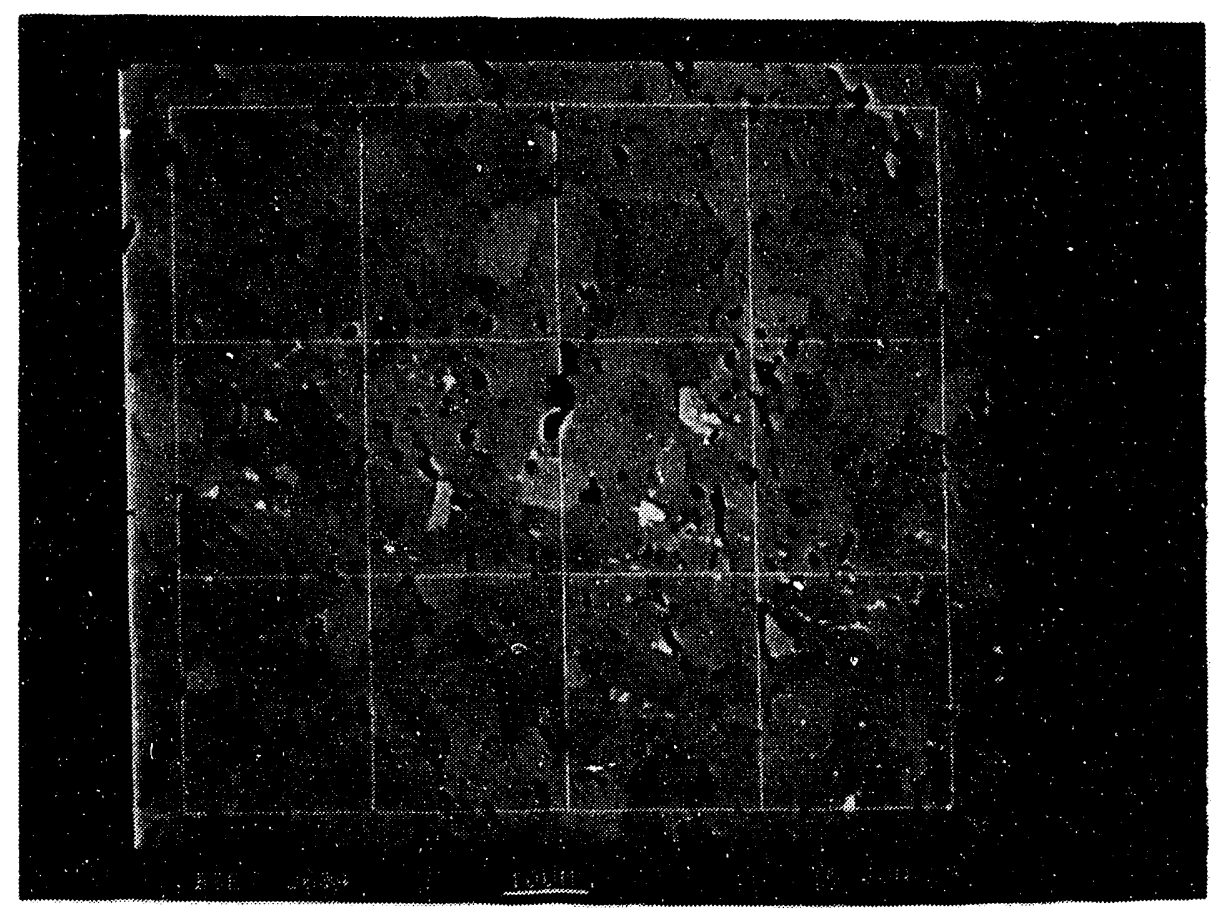

Figure 1. Back-scatter electron-probe microanalysis (EPMA) photograph of silicon carbide test material. 
Shock Compression Properties of Silicon Carbide

(Intentionally Left Blank) 


\section{Experimental Method}

Uniaxial-strain compressive shock and release waves were produced in the monolithic silicon carbide with a single-stage powder-gun facility. The $89-\mathrm{mm}$ diameter smooth-bore gun is capable of achieving a maximum impact velocity slightly above $2.3 \mathrm{~km} / \mathrm{s}$. Three electrically shorting pins were used to measure the velocity of the projectile at impact. Four similar pins were mounted flush to the impact plane and used to monitor the planarity of impact. The pins were also used to trigger diagnostic equipment: the interferometer laser, various recording oscilloscopes and transient digitizers. Projectile velocity could be measured with an accuracy of $\sim 0.5 \%$ and the deviation from planarity of impact was typically about $10^{-3}$ radians.

A typical experimental configuration for the series of tests is shown in Figure 2. A disc of the ceramic being tested is mounted in the projectile and is supported on the main projectile body by a disc of low density polyurethane foam approximately $7 \mathrm{~mm}$ in thickness. Both 20 and 40 pounds per cubic foot $\left(320\right.$ and $\left.640 \mathrm{~kg} / \mathrm{m}^{3}\right)$ foam were used in the present study. An aluminum ring encloses the ceramic disc as shown and provides a coplanar impact surface for electrically shorting the various diagnostic pins. For the highest impact stress experiment a tantalum plate replaced the ceramic plate in the projectile. In the partial release and recompression experiment the impacting disc was lithium fluoride approximately $3.3 \mathrm{~mm}$ in thickness backed by a $1.5 \mathrm{~mm}$ tantalum disc.

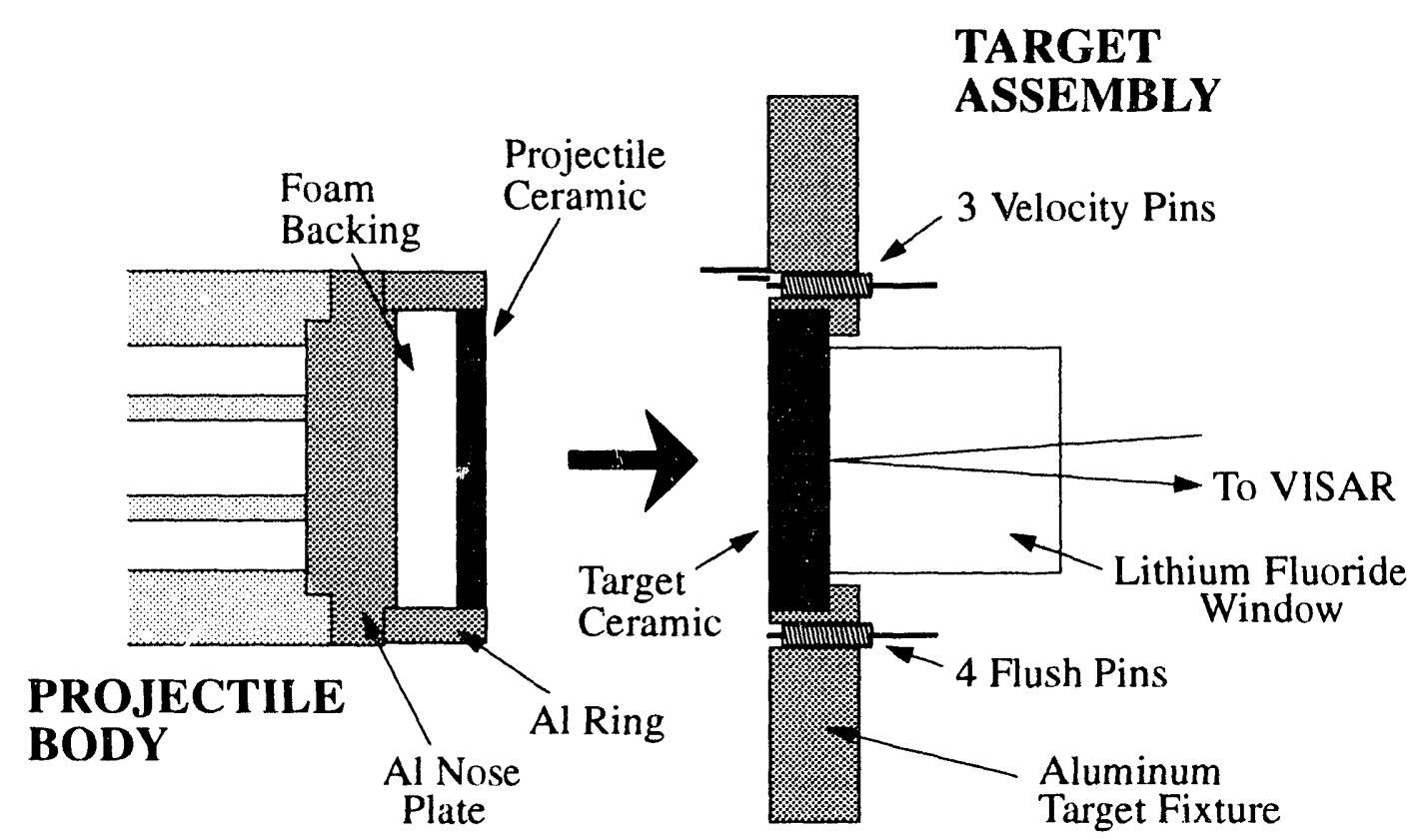

Figure 2. Experimental configuration for shock and release experiments on silicon carbide. 
For the target, a disc of the ceramic was mounted in the stationary supporting target fixture. An optical quality disc of single crystal lithium fluoride was intimately bonded with epoxy to the back of this ceramic sample. All critical surfaces were lapped and polished, and were typically flat to within a few bands of sodium light. The bonded lithium fluoride surface was first lightly diffused and vapor-deposited with about $100 \mathrm{~nm}$ of aluminum. The ceramic-lithium fluoride epoxy-bond thickness was approximately 10 to $20 \mu \mathrm{m}$.

The ceramic-on-ceramic planar impact produced a compressive wave of uniaxial strain which propagated across the stationary ceramic specimen and through the ceramic-lithium fluoride interface. An equivalent compressive wave propagated through the projectile ceramic specimen and reflected at the low-impedance foam interface as a release wave which unloaded the compressed ceramic. Dimensions of the ceramic discs were selected such that lateral release waves from the boundaries of the disc did not interfere with the central motion until after the experimental measurement was completed. Similar motions were induced when a tantalum impact plate was used. In the ceramic-on-ceramic impacts the release wave traveled uninterrupted through the impact interface whereas, in the tantalum impactor case, additional wave interactions occurred at the tantalum-ceramic interface.

The compression- and release-wave behavior was measured by monitoring the time-resolved longitudinal motion at the center of the ceramic-lithium fluoride interface with laser velocity-interferometry (VISAR) techniques [Barker and Hollenbach, 1972]. Measurements were recorded on transient digitizers with a sampling period of $0.742 \mathrm{~ns}$ per data point. Lithium fluoride was used as the laser window material because, although its mechanical impedance is somewhat lower than the ceramic being tested, it is the only material which has been optically calibrated and which remains transparent when subjected to the 10 to $50 \mathrm{GPa}$ shock stresses generated in the present experiments [Wise and Chhabildas, 1986].

The interference fringes measured with the VISAR system were converted to a time-resolved history of the velocity of the interface using he method of Barker and Hollenbach (1972), with a time resolution of approximately $1 \mathrm{~ns}$. The amplitude resolution is approximately $2 \%$ of one fringe. Typically two to three fringes are achieved in the interface acceleration through the compressive shock front. From these records the dynamic stress and strain characteristics of the ceramics were determined through further computational and analytic techniques described in a later section.

A total of five shock compression experiments were performed on silicon carbide. The lowest impact velocity achieved a Hugoniot state below the Hugoniot elastic limit and provided useful nonlinear elastic and spall properties of the ceramic. The rem:aining experiments ranged up to Hugoniot states of approximately $50 \mathrm{GPa}$ which is about three times the Hugoniot elastic limit for this material. The impact velocities and experimental dimensions for the series of experiments are provided in Table 1.

In all tests lithium fluoride windows $25.4 \mathrm{~mm}$ in thickness and $50.8 \mathrm{~mm}$ in diameter were used. The silicon carbide discs were approximately $50 \mathrm{~mm}$ in diameter. Note that a tantalum impactor ( $88 \mathrm{~mm}$ in diameter) was used to achieve the highest impact stress in 
Table 1:

Experimental Conditions for Silicon Carbide Impact Tests

\begin{tabular}{|c|c|c|c|c|c|c|}
\hline $\begin{array}{c}\text { Test } \\
\text { Number }\end{array}$ & $\begin{array}{c}\text { Target } \\
\text { Material }\end{array}$ & $\begin{array}{c}\text { Impactor } \\
\text { Material }\end{array}$ & $\begin{array}{c}\text { Foam } \\
\text { Density }\end{array}$ & $\begin{array}{c}\text { Impact } \\
\text { Velocity }\end{array}$ & $\begin{array}{c}\text { Target } \\
\text { Thickness }\end{array}$ & $\begin{array}{c}\text { Impactor } \\
\text { Thickness }\end{array}$ \\
\hline & & & $\left(\mathrm{kg} / \mathrm{m}^{3}\right)$ & $(\mathrm{km} / \mathrm{s})$ & $(\mathrm{mm})$ & $(\mathrm{mm})$ \\
\hline \hline $\mathrm{CE}-4$ & $\mathrm{SiC}$ & $\mathrm{SiC}$ & 320 & 1.542 & 8.939 & 3.987 \\
\hline $\mathrm{CE}-5$ & $\mathrm{SiC}$ & $\mathrm{SiC}$ & 640 & 2.100 & 8.940 & 3.995 \\
\hline $\mathrm{CE}-31$ & $\mathrm{SiC}$ & $\mathrm{Ta}$ & 640 & 2.118 & 8.956 & 1.516 \\
\hline $\mathrm{CE}-32$ & $\mathrm{SiC}$ & $\mathrm{SiC}$ & 320 & 0.612 & 9.841 & 4.958 \\
\hline CE-42 & $\mathrm{SiC}$ & $\mathrm{LiF}+\mathrm{Ta}^{\mathrm{a}}$ & - & 2.206 & 4.963 & $3.297+1.51^{\mathrm{a}}$ \\
\hline \multicolumn{6}{|l}{${ }^{\mathrm{a}}$ Layered impactor - lithium fluoride backed by tantalum. } \\
\hline
\end{tabular}

Test CE-31. A layered lithium fluoride and tantalum impactor was used in tesi CE-42 to achieve; specific partial release and recompression states in the silicon carbide.

One profile of the measured interface velocity is shown in Figure 3 to illustrate the nature of the compression- and release-wave data. Profiles for all tests are provided in the Appendix. The compression profile reveals the elastic-plastic wave-profile character of the

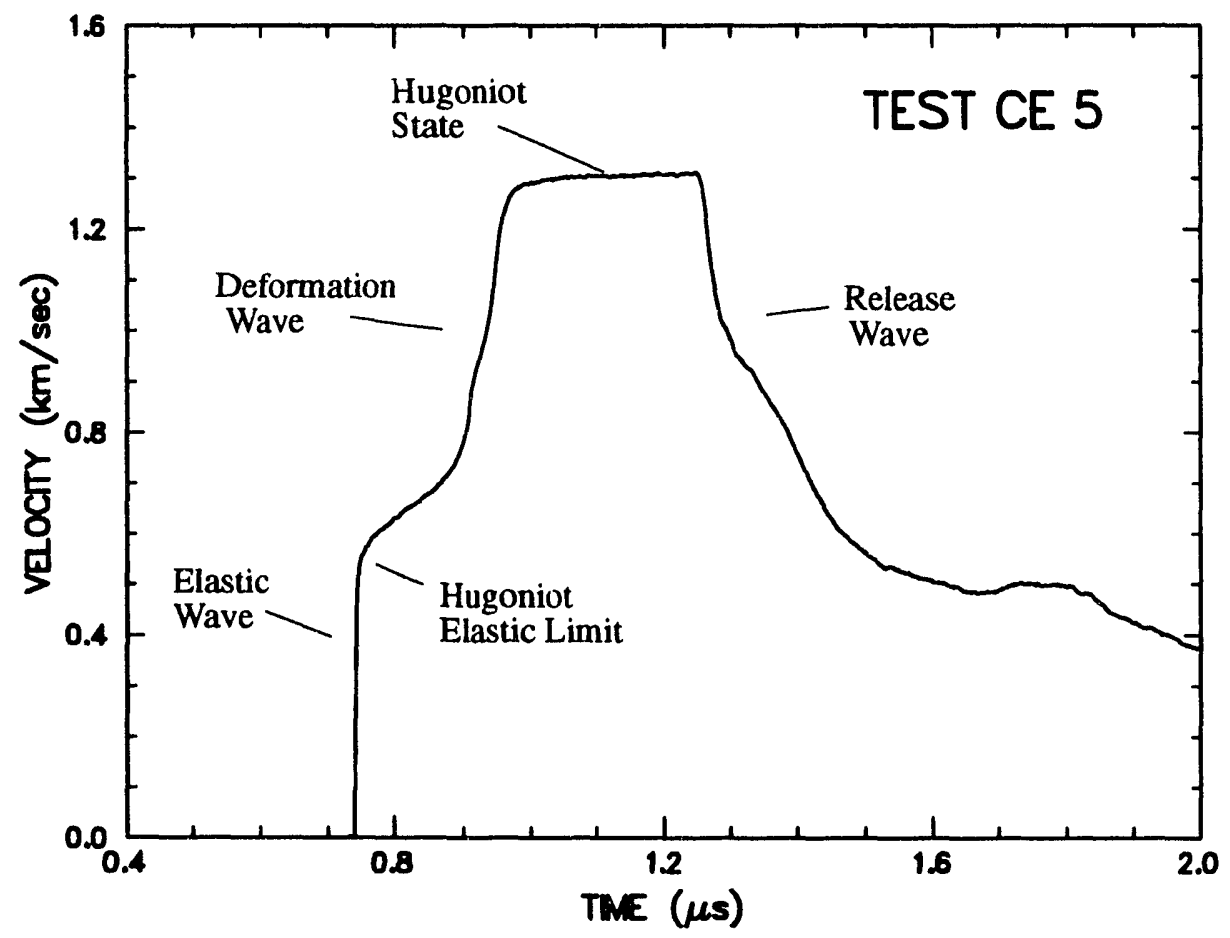

Figure 3. Silicon carbide interface velocity profile for Test CE-5. 
uniaxial deformation process. The second small wavelet at about $0.9 \mathrm{~km} / \mathrm{s}$ in the compressive profile between the elastic and plastic waves has been shown from computer solutions to be a consequence of a reflection at the ceramic-window interface due to the mechanical impedance mismatch and is not a material-property feature. Elastic and deformation characteristics upon release from the Hugoniot state were provided by the unloading portion of the profile in Figure 3. Late-time behavior (greater than about $2 \mu \mathrm{s}$ ) is not meaningful because lateral release waves from the sample edges can be expected to compromise the uniaxial nature of the motion. 


\section{Hugoniot Properties}

The wave-profile data shown in Figure 3 and provided in the Appendix can be used to determine the Hugoniot properties of the silicon carbide ceramic. Here, Hugoniot states refer to the peak stress-volume-particle-velocity states achieved in the shock-compression process, recognizing that nonsteady-wave characteristics may compromise this definition. Analysis of the Hugoniot states were accomplished in several ways. In one method distinct elastic and plastic waves were first identified in the compressive profiles. By assuming steady-wave behavior, shock-wave velocities and particle-velocity increments were determined for both waves. Hugoniot relations, accounting for impedance mismatch at the recording interface, were then used to calculate the Hugoniot states. This method gave resultd in accord with Hugoniot properties determined from interface or free-surface measurements of earlier workers [e.g., Gust, et al., 1973].

Table 2:

Hugoniot Data for Silicon Carbide

\begin{tabular}{|c|c|c|c|c|c|c|c|c|}
\hline & \multicolumn{3}{|c|}{$-\cdots-$ Elastic State -- } & \multicolumn{4}{c|}{--.-- Plastic State ---.- } \\
\hline $\begin{array}{c}\text { Test } \\
\text { Number }\end{array}$ & $\begin{array}{c}\text { Shock } \\
\text { Velocity }\end{array}$ & $\begin{array}{c}\text { Particle } \\
\text { Velocity }\end{array}$ & Stress & $\begin{array}{c}\text { Specific } \\
\text { Volume }\end{array}$ & $\begin{array}{c}\text { Shock } \\
\text { Velocity }\end{array}$ & $\begin{array}{c}\text { Particle } \\
\text { Velocity }\end{array}$ & Stress & $\begin{array}{c}\text { Specific } \\
\text { Volume }\end{array}$ \\
\hline & $(\mathrm{km} / \mathrm{s})$ & $(\mathrm{km} / \mathrm{s})$ & $(\mathrm{GPa})$ & $\left(\mathrm{m}^{3} / \mathrm{Mg}\right)$ & $(\mathrm{km} / \mathrm{s})$ & $(\mathrm{km} / \mathrm{s})$ & $(\mathrm{GPa})$ & $\left(\mathrm{m}^{3} / \mathrm{Mg}\right)$ \\
\hline \hline CE-4 & $12.50^{*}$ & 0.397 & 15.77 & 0.3048 & 9.43 & 0.771 & 27.61 & 0.29 .28 \\
\hline CE-5 & $12.50^{*}$ & 0.383 & 15.20 & 0.3051 & 9.63 & 1.050 & 36.34 & 0.2839 \\
\hline CE-31 & $12.50^{*}$ & 0.376 & 14.91 & 0.3053 & 10.03 & 1.422 & 48.78 & 0.2729 \\
\hline CE-32 & $12.29^{*}$ & 0.306 & 11.95 & 0.3069 & - & - & - & - \\
\hline \hline
\end{tabular}

*Elastic shock velocity is calculated (see text).

Hugoniot states determined by this analytic method are provided in Figure 4 and Table 2. In the present experiments a measurement of the elastic precursor wave velocity was not made. The precursor wave velocity provided in Table 2 was estimated from the measured longitudinal ultrasonic velocity corrected for elastic nonlinearity to the Hugoniot elastic limit state by assuming a linear shock-velocity versus particle-velocity behavior $\left(U_{s}=C_{l}+S_{l} u_{p}\right.$ ) with $S_{l}=1$ (consistent with the slope of high-pressure shock-versus particle-velocity data for silicon carbide). Further computational analysis on the nonlinear elastic shock and release profile provided by experiment CE-32 supports this estimate [Kipp and Grady, 1992]. 
The Hugoniot elastic limit states plotted in Figure 4 and provided in Table 2 correspond to the particle velocity amplitude of the initial breakover of the elastic shock in the measured wave profile. This initial yield state does not include the subsequent pressure hardening or ramp up observed immediately behind the precursor shock which would lead to a slightly higher particle velocity level. In determining the amplitude of the particle velocity jump through the plastic wave, a more central value for the first wave amplitude was determined from the data.

The compression and release stress-volume behavior of the material was also determined with computational methods [Kipp and Grady, 1989]. With these methods a one-dimensional wave code, WONDY (Kipp and Lawrence, 1982), in conjunction with an empirical constitutive model for the ceramic was used iteratively to determine the stress-volume characteristics. Material parameters used in the calculations are listed in Table 3. Parameters in the model were adjusted until agreement with the measured velocity profile was achieved. The corresponding stress-volume behavior determined in the calculation was then accepted as the dynamic material response. Stress-volume paths determined by this method are shown in Figure 4. The peak stress states agree well with the previous Hugoniot analysis and are provided in Table 4.

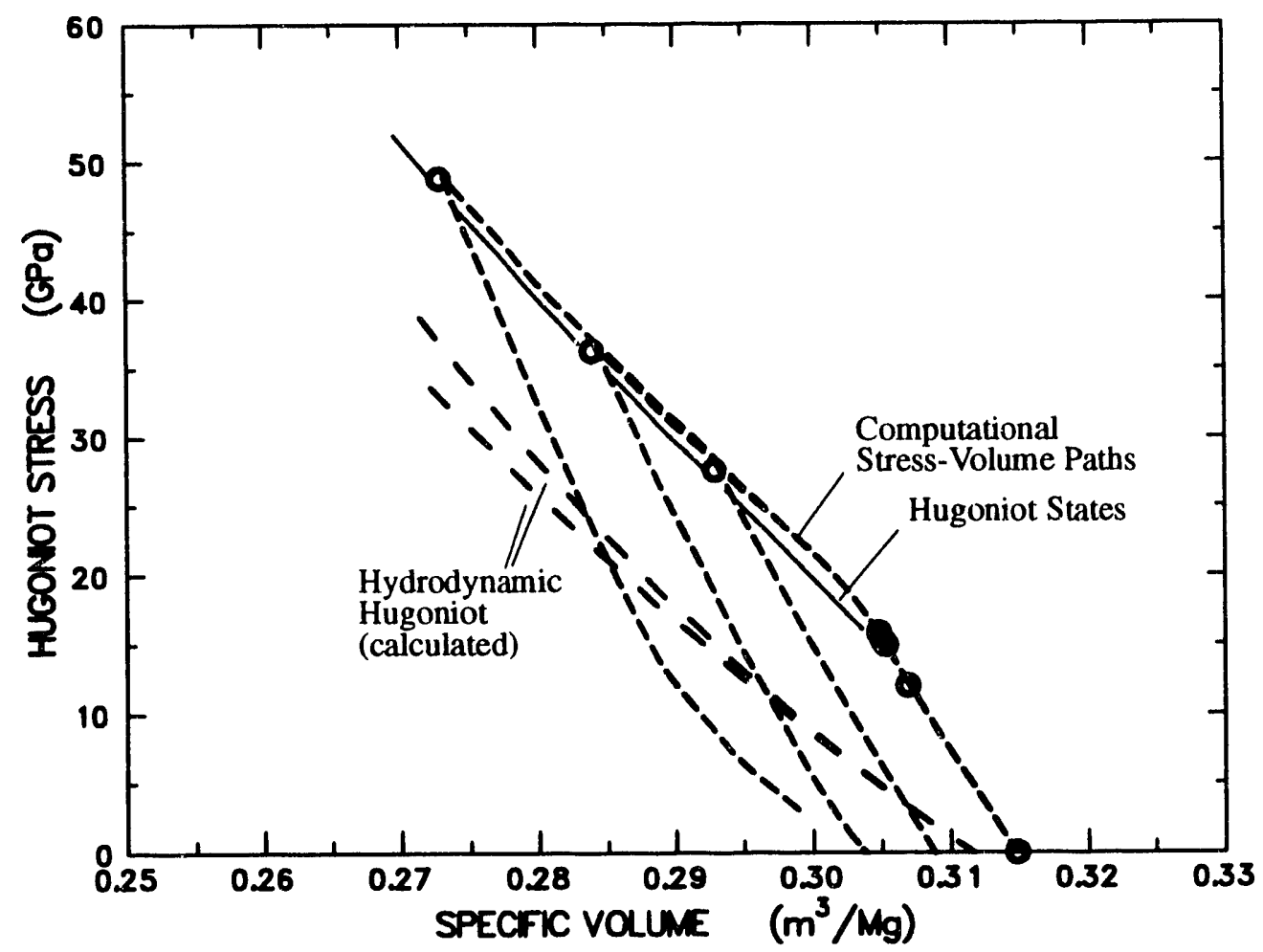

Figure 4. Hugoniot states and dynamic stress-volume paths calculated from wave profile data. 


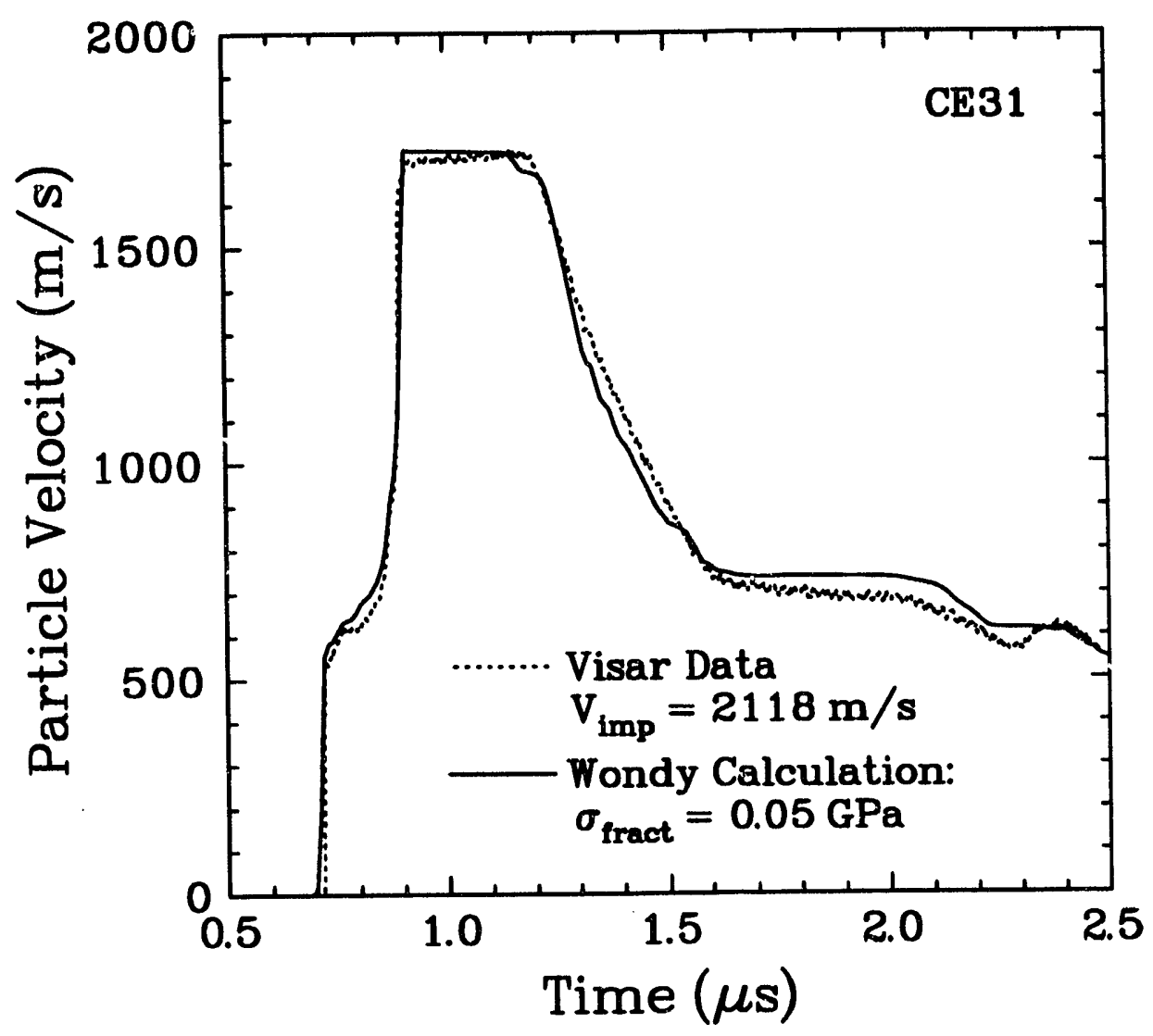

Figure 5. Comparison of VISAR wave profile for test CE-31 and Wondy wave-code solution with strain-hardening elasticplastic model for silicon carbide.

The corresponding fits to the particle velocity data for the two lower amplitude experiments, CE-4 and CE-5, have been reported by Kipp and Grady (1989). The comparison of calculated and experimental particle velocity histories for the highest amplitude experiment, CE-31, is shown in Figure 5. Note that the calculation captures nearly all of the character of the data, except the initial structure of the release at $1.2 \mu \mathrm{s}$, where the effect of the $0.75 \mathrm{GPa}$ yield in the tantalum is too pronounced. This calculation used the same parameters as those reported by Kipp and Grady (1989) for the SiC (cf. Table 3) in a strainhardening model ( 6 term fit, with an initial yield of $13.0 \mathrm{GPa}$; the 6 pairs of the hardening fit are $\left(Y_{i} \mathrm{GPa}, \mathrm{x}_{\mathrm{i}}\right.$ weight $)=(13.0,0.307),(14.5,0.231),(16.0,0.152),(17.0,0.076)$, $(19.0,0.115)$, and $(20.0,0.115))$ to reproduce the transition from elastic to permanent deformation states (State 4 in WONDY). 
Table 3: Material Properties

\begin{tabular}{|c|c|c|c|c|c|c|}
\hline Material & $\begin{array}{c}\text { Reference } \\
\text { Density }\end{array}$ & $\begin{array}{c}\text { Sound } \\
\text { Speed }\end{array}$ & Slope & $\begin{array}{c}\text { Gruneisen } \\
\text { Coefficient }\end{array}$ & $\begin{array}{c}\text { Poisson's } \\
\text { Ratio }\end{array}$ & $\begin{array}{c}\text { Initial } \\
\text { Yield }\end{array}$ \\
\hline \hline Foam & 640 & 1500 & 2.0 & 1.0 & $\sim$ & $(\mathrm{GPa})$ \\
\hline Tantalum & 16650 & 3293 & 1.307 & 1.60 & 0.335 & 0.75 \\
\hline $\mathrm{LiF}$ & 2641 & 5148 & 1.353 & 1.50 & $\sim$ & $\sim$ \\
\hline $\mathrm{SiC}$ & 3177 & 8186 & 1.0 & 1.0 & 0.160 & 13.0 \\
\hline $\mathrm{Al}$ & 2758 & 5328 & 1.338 & 2.0 & 0.333 & 0.30 \\
\hline
\end{tabular}

In the experiment CE-32, the elastic behavior of the material was examined using SWAP (Barker and Young, 1974), which uses a solution technique based on the x-t characteristics. This code provides for sharp shocks and incremental steps for structured waves. Assuming a linear shock-particle velocity relationship for the Hugoniot, the correct slope of the release wave could be obtained with an $S_{1}$ of 1.25 , but the ultrasonic longitudinal velocity of $12060 \mathrm{~m} / \mathrm{s}$ for the reference velocity $C_{l}$ resulted in a pulse width that was too short by about $3 \%$. A reference velocity of $C_{l}=11700 \mathrm{~m} / \mathrm{s}$ was required to widen the pulse width sufficiently to agree with the measured pulse width (Figure 6).

The calculated Hugoniot state properties for the four experiments are tabulated in Table 4. When compared to the corresponding entries in Table 2 (Plastic State for CE-4, CE-5, and CE-31, and Elastic State for CE-32), excellent agreement is observed in the two approaches to determine the Hugoniot state values.

Table 4: WONDY Calculations of Hugoniot States

\begin{tabular}{|l|c|c|c|c|c|}
\hline $\begin{array}{c}\text { Test } \\
\text { Number }\end{array}$ & $\begin{array}{c}\text { Particle } \\
\text { Velocity }\end{array}$ & Density & $\begin{array}{c}\text { Specific } \\
\text { Volume }\end{array}$ & Stress & $\begin{array}{c}\text { Longitudinal } \\
\text { Sound Speed }\end{array}$ \\
\hline & $(\mathrm{m} / \mathrm{s})$ & $\left(\mathrm{kg} / \mathrm{m}^{3}\right)$ & $\left(\mathrm{m}^{3} / \mathrm{Mg}\right)$ & $(\mathrm{GPa})$ & $(\mathrm{m} / \mathrm{s})$ \\
\hline \hline CE-4 & 771 & 3412 & 0.2931 & 27.85 & 12923 \\
\hline CE-5 & 1050 & 3518 & 0.2843 & 36.62 & 13277 \\
\hline CE-31 & 1421 & 3660 & 0.2732 & 49.01 & 13713 \\
\hline CE-32 & 306 & 3257 & 0.3070 & 12.05 & 12368 \\
\hline
\end{tabular}




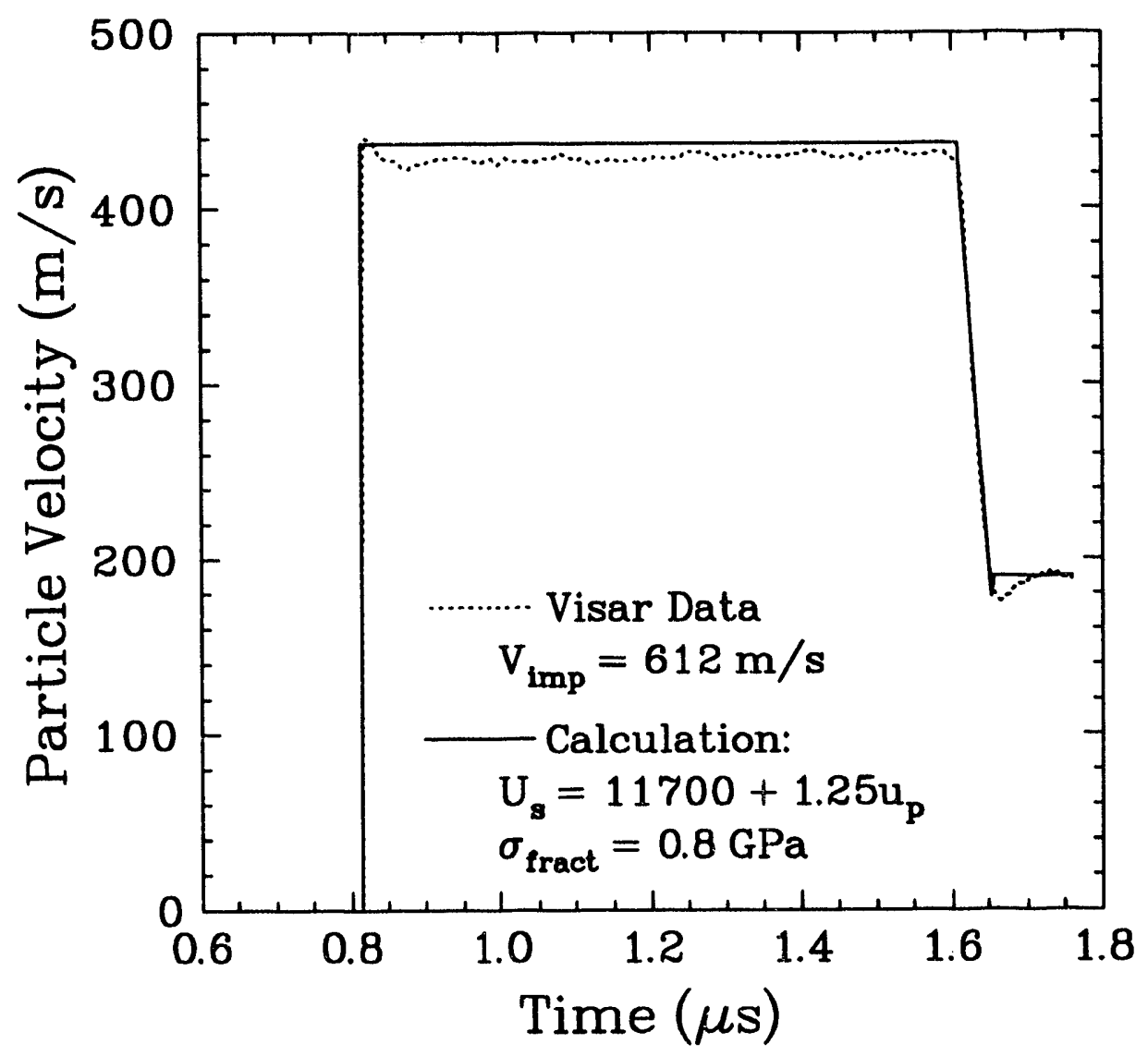

Figure 6. Comparison of VISAR wave profile for test CE-32 and SWAP wave-code solution. 
Shock Compression Properties of Silicon Carbide

(Intentionally Left Blank) 


\section{Strength Properties}

The Hugoniot elastic limit identifies initial yield in the ceramic and provides an estimate of the initial dynamic material strength. The assumption that the Hugoniot elastic limit accurately characterizes the post-yield shear strength, however, can be seriously in error. Accumulated inelastic deformation along with the changing confining pressure as the Hugoniot state is approached in the plastic wave can markedly alter the strength of the material.

The strength at the Hugoniot state can be determined from the shock-wave data through direct comparison of the longitudinal Hugoniot stress states with the hydrodynamic or mean stress state of the material at the same specific volume. The hydrodynamic properties are usually not well known, however, and are frequently estimated by theoretical extrapolation of ultrasonic data. Nevertheless, the very high strength of the ceramics of interest makes this technique a reasonable method for calculating dynamic strength properties.

Because of the inertially constrained condition of uniaxial strain in the planar impact configuration, $\left(\varepsilon_{x}=1-\rho_{o} / \rho, \varepsilon_{y}=\varepsilon_{z}=0\right)$, the resolved shear stress, $\tau=\left(\sigma_{x}-\sigma_{y}\right) / 2$, within the elastic shock wave increases until the dynamic yield strength of the material is achieved at an average confining pressure, $p=\left(\sigma_{x}+2 \sigma_{y}\right) / 3$. The axial stress at this critical point is identified as the Hugoniot elastic limit, $\sigma_{x}=\sigma_{h e l}$, and the equivalent unconfined yield strength, $Y=2 \tau$ assuming von Mises yield conditions and linear elasticity within the yield surface is,

$$
Y=2 \frac{C_{s}^{2}}{C_{l}^{2}} \sigma_{h e l} .
$$

Hugoniot elastic limit values for Eagle Picher silicon carbide are provided in Table 2. A nominal yield strength calculated for silicon carbide from Equation (1) is $Y=12.4 \mathrm{GPa}$, based on a Hugoniot elastic limit of $\sigma_{h e l}=15.3 \mathrm{GPa}$.

Calculation of the post-yield dynamic strength at the Hugoniot state through comparison of the axial stress states measured in the planar impact experiment with the corresponding pressure-volume states is illustrated in Figure 7. The measured axial stress $\sigma_{x}$ and the corresponding transverse stress $\sigma_{y}$ will relate to the mean pressure curve as shown in Figure 7a. The post-yield resolved shear strength at subsequent Hugoniot states is calculated through comparison of the mean stress and axial stress behavior at the same specific volume through the relation,

$$
\tau=\frac{3}{4}\left(\sigma_{x}-p\right)
$$

Materials can exhibit different strength behavior with increasing Hugoniot stress (Figure 7b). Ideal plasticity would imply constant strength (constant offset between the 


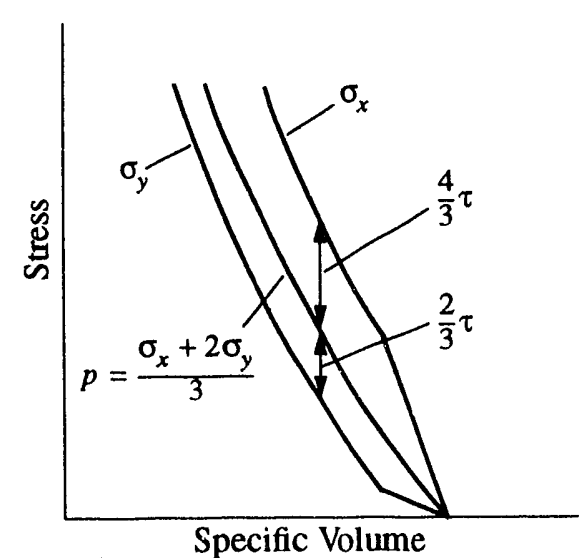

(a)

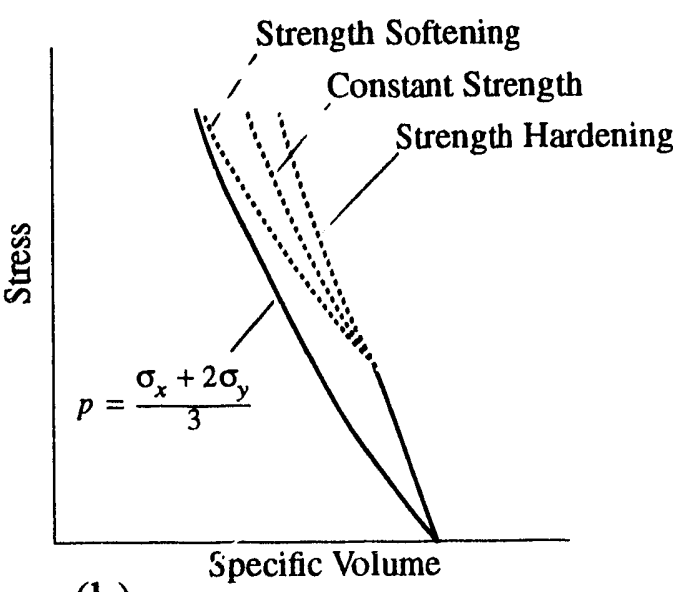

(b)

Figure 7. Strength properties of an elastic-plastic material.

mean stress and Hugoniot stress states). Both strength hardening and strength softening on the Hugoniot have also been observed for other ceramics (Kipp and Grady, 1989).

The pressure-volume compression curves for most of the high strength ceramics of interest have not been measured. Quite useful estimates of the hydrodynamic behavior, however, can be established from the reasonably mature understanding of the systematics of solid-state compressibility. Fi nite strain Burch-Murnaghan, or equivalently, linear shockvelocity versus particle-velocity, representations of material compressibility [Jeanloz, 1989] adequately describe the pressure-volume response of most single phase solids to $20 \%$ strains or higher. For the latter representation, two parameters $C_{o}$ and $S_{o}$ in a linear shock velocity versus particle velocity relation along with the initial theoretical solid density $\rho_{o}$ of the material leads to a hydrodynamic pressure versus specific-volume relation for the material,

$$
p=\frac{\rho_{o} C_{o}^{2} \varepsilon}{\left(1-S_{o} \varepsilon\right)^{2}},
$$

where the volume strain is $\varepsilon=\varepsilon_{x}=1-\rho_{o} / \rho$.

The theoretical density is known for the material and $C_{o}$ can be calculated from the ultrasonic elastic bulk modulus, $C_{o}=\sqrt{K_{o} / \rho_{o}}$. The nonlinearity parameter $S_{o}$ can be obtained from high pressure Hugoniot data or, alternatively, can be calculated from the relation $S_{o}=\left(K_{o}^{\prime}+1\right) / 4$ where $K_{o}^{\prime}=d K_{o} / d p$ is the adiabatic pressure derivative of the bulk modulus. High-pressure Hugoniot data indicate that $S_{o}$ is close to 1.0 for silicon carbide [Gust, et al, 1973]. Data from Aleksandrov et al (1990) provide $K_{o}{ }^{\prime}=3.9 \pm 0.2$ which yields $S_{o} \cong 1.2$. Reasonable estimates of the mean stress behavior are compared with Hugoniot states in Figure 4. The two curves assume $S_{o}=0.8$ and $S_{o}=1.2$, respectively. These results were used to establish the post-yield shear-stress states shown in Figure 8. 


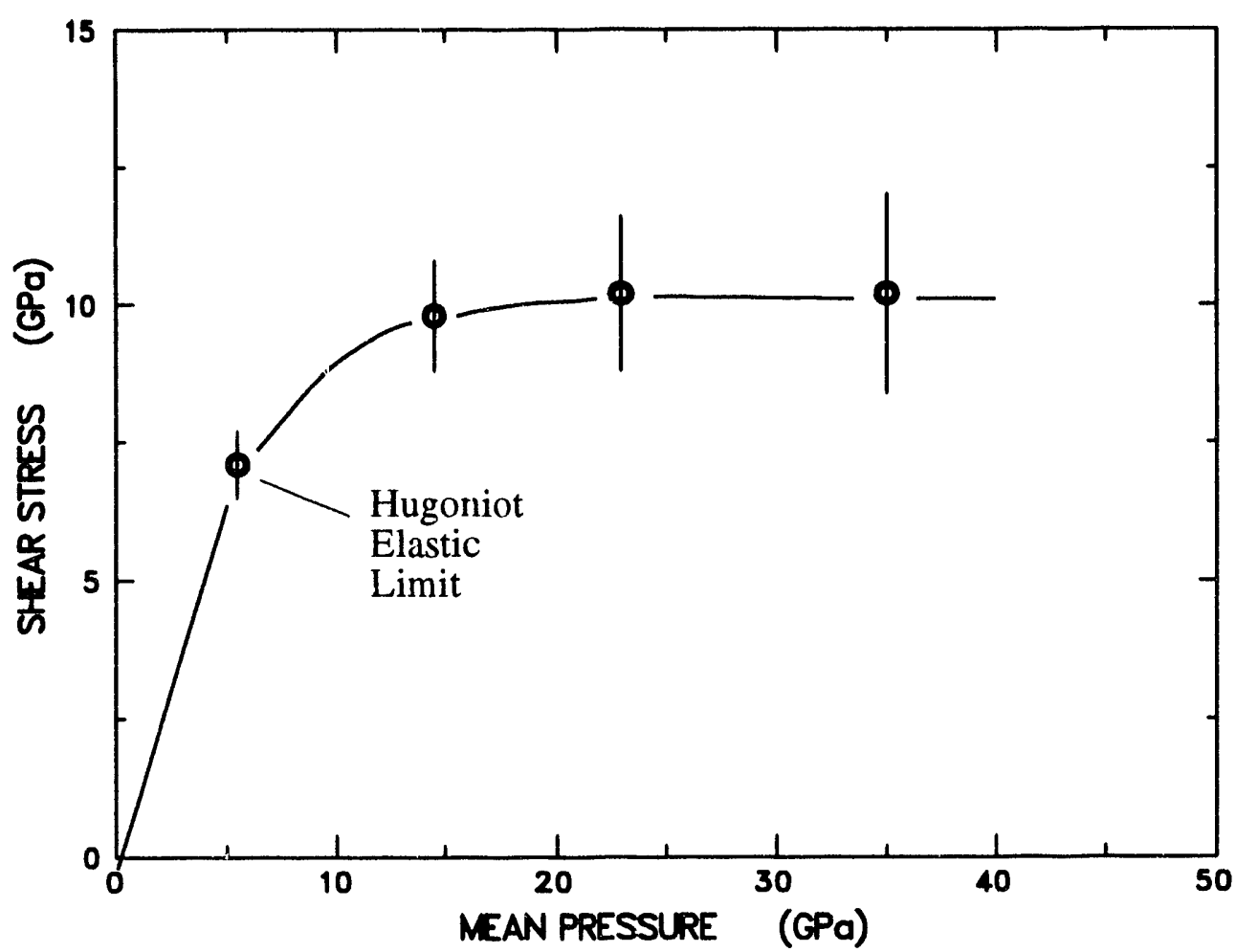

Figure 8. Shear stress at the Hugoniot state inferred from Hugoniot and calculated hydrodynamic curve.

Several material complications can affect the analysis just described. First, impurities which are introduced in the processing of commercial ceramics, if in sufficient quantities, can shift the calculated hydrodynamic curve and must be accounted for. Second, porosity, which exists in virtually all ceramics, must be crushed out before the mean stress curve and the hydrodynamic curve coincide. In general this crush curve is not known. In calculating a shear strength at the Hugoniot state for the three experiments it was assumed that complete pore collapse was achieved and comparison with the theoretical-density hydrodynamic curve was made. The difference between twice the shear strength at the Hugoniot elastic limit (Figure 8) and the dynamic yield calculated from Equation 1 is probably a consequence of porosity complications in the analysis.

In Figure 8 an initial dynamic yield of approximately $7 \mathrm{GPa}$ is observed to harden to about $10 \mathrm{GPa}$ with increasing Hugoniot stress. Uncertainties are larger at higher pressures because of corresponding uncertainties in the mean stress curve. Post-yield stress hardening is also indicated by the ramp character of the measured wave profiles immediately following the elastic precursor wave. Although pressure hardening is commonly used to model the shear-strengthening properties of silicon carbide, inelastic strain or strain-rate hardening cannot be ruled out. 
Shock Compression Properties of Silicon Carbide

(Intentionally Left Blank) 


\section{Release Properties}

'The present planar impact experiments on ceramic materials were designed so that shock compression followed by dynamic decompression and stress release, under controlled uniaxial strain conditions, were achieved. The release portion of the measured wave profile provides dynamic material property data on the cyclic or hysteretic behavior of the stress-loaded ceramic. Release and hystereses properties determine energy absorption and transmission characieristics of material elements and consequently influence the overall penetration stopping resistance of high-strength ceramics. Release-wave dispersion data have been used to infer the confining pressure dependence of shear strength during stress unloadirg [Chen, 1991] and reverse plasticity properties [Steinberg, 1990]. Further, during high velocity penetration, material compressibility must be correctly modelled. $\mathrm{Re}-$ lease-wave measurements provide high-pressure elasticity data needed to properly model finite compressibility.

Release properties of the ceramic were determined from the wave profile data through arrival time and structure of the release wave immediately following the peak plateau in the wave profile (Figure 3 ). Dispersion (spreading) of the release wave is a consequence of elastic nonlinearity and inelastic deformation characteristics of the material during uniaxial unloading. Both molecular and microstructural properties of the ceramic at high pressure play a role in determining this feature of the wave propagation process.

Extraction of material property data from the release-wave behavior through analytic methods involves difficulties not encountered in the compressive Hugoniot analysis [Grady, 1991]. Assumptions are necessary which are difficult to assess and may or may not be acceptable. Certain material property features such as the nonlinear elastic properties near the shock state can be determined by analytic methods. Other properties are more easily extracted through interactive computer analysis [Kipp and Grady, 1989].

Longitudinal sound velocity $C_{l}$ and the corresponding longitudinal modulus,

$$
K_{l}=\rho \frac{d \sigma}{d \rho}=\rho C_{l}^{2},
$$

determined from the three experiments involving symmetric silicon carbide impact are plotted in Figure 9. These data were determined from the transit time of the first arrival of the release wave. Eulerian or spatial wave velocities and corresponding moduli are plotted in the Figure. Note that values are several percent lower than those inferred from computational solutions (Table 4). Ultrasonic values for longitudinal velocity and modulus are also shown. The observed discrepancy between ultrasonic data and the shock data extrapolated to zero pressure density is attributed to the percent level porosities in the ceramic samples.

In Figure 10 the stress derivative of the modulus, $K_{l}^{\prime}=d K_{l} / d \sigma$ is plotted. These data were calculated directly from individuai profiles by calculating the initial slope of each individual release wave through the expression, 


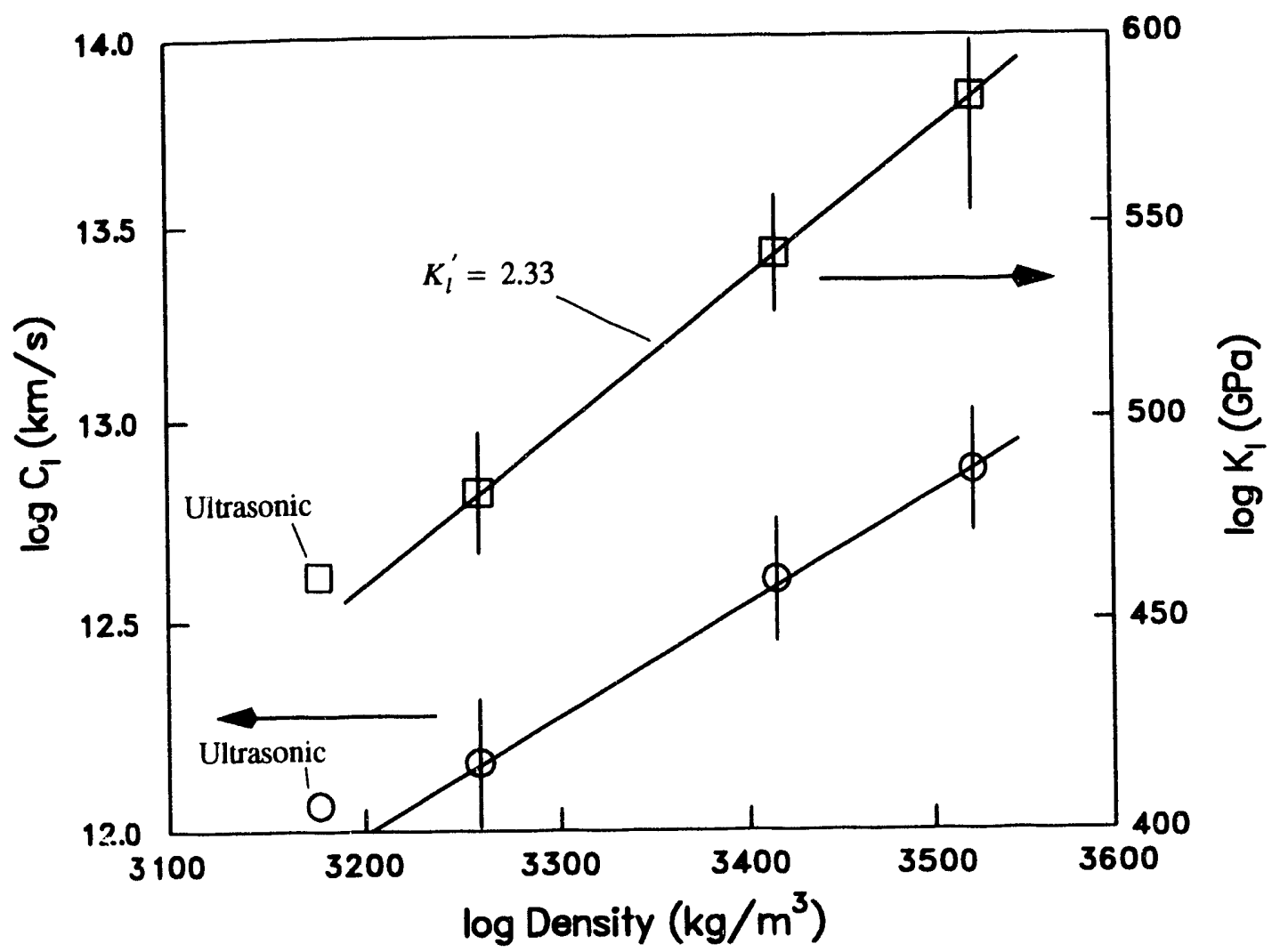

Figure 9. Initial release velocity and longitudinal modulus at the Hugoniot state. Ultrasonic data correspond to points at initial density of $3177 \mathrm{~kg} / \mathrm{m}^{3}$.

$$
K_{l^{*}}^{\prime}=\frac{d}{d \sigma} \rho_{o} C_{l^{*}}^{2}=\rho_{o} \frac{d C_{l^{*}}^{2}}{d u} \frac{d u}{d \sigma}=\rho_{o} \frac{d C_{l^{*}}^{2}}{d u} \frac{1}{\rho_{o} C_{l^{*}}}=2 C_{l^{*}}^{\prime}
$$

The starred properties in Equation 5 correspond to Lagrangian velocities or moduli. Note that both stress and particle-velocity derivatives are implied. The Eulerian modulus was then provided by,

$$
K_{l}^{\prime}=\frac{\rho_{o}}{\rho} K_{l^{*}}-1
$$

The data in Figure 10 indicate a decreasing $K_{l}^{\prime}$ with increasing density. From the slope of the data in Figure 10 it was determined that $K_{l} K_{l}^{\prime \prime}=-24.9$. This property compares well in both sign and magnitude with comparable bulk moduli data on alkali halides [Ruoff and Chhabildas, 1979]. It is nearly identical to the very accurate measurement made on $\mathrm{NaCl}$ by Chhabildas and Ruoff (1976). 


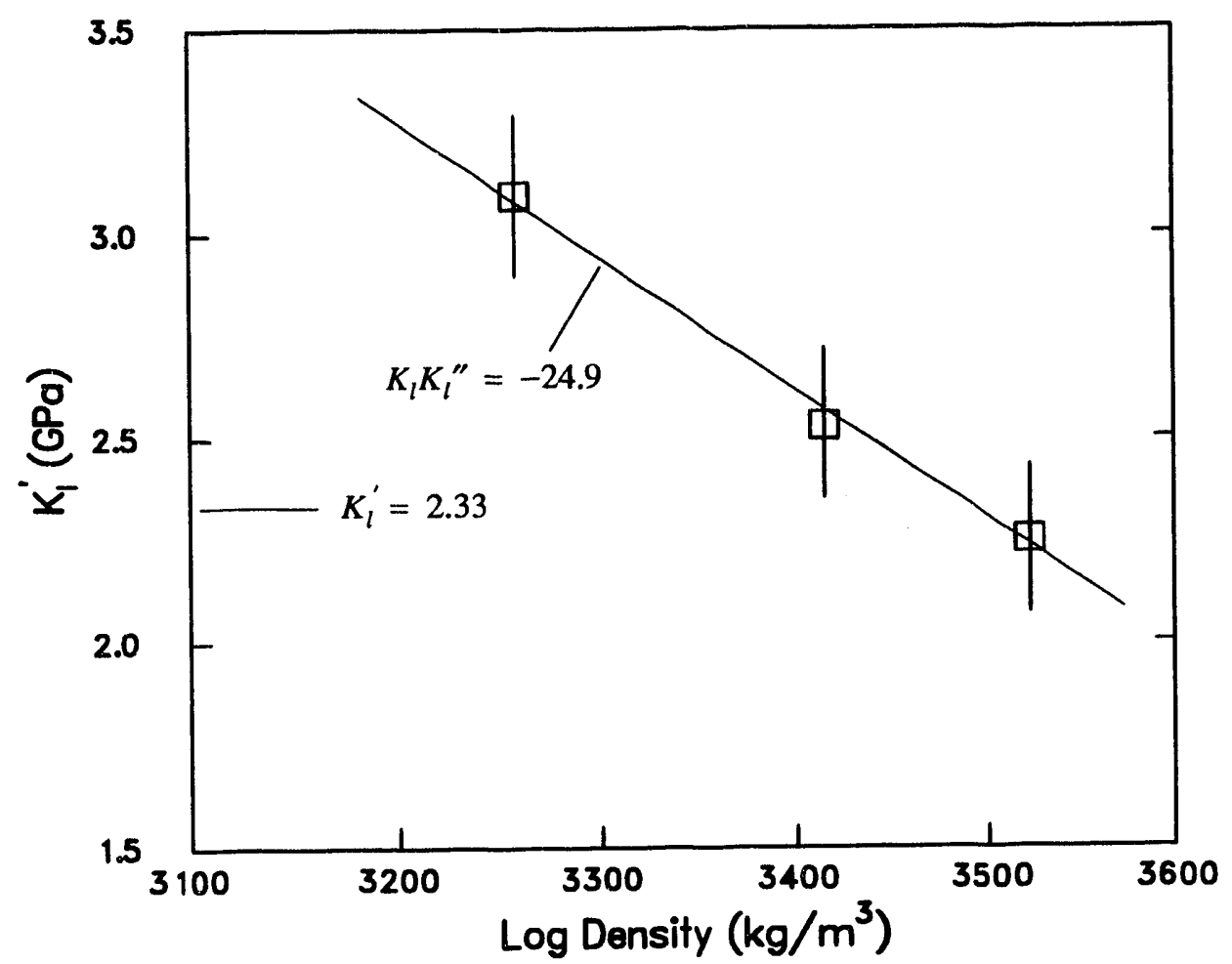

Figure 10. Stress derivative of the release moduli for silicon carbide from initial dispersion of unloading wave.

The stress derivative of the modulus can also be calculated from the data in Figure 9 through,

$$
K_{l}^{\prime}=\frac{d K_{l} / d \rho}{K_{l} / \rho}
$$

A value of $K_{l}{ }^{\prime}=2.33$ was calculated and is in reasonable agreement with the independent data of Figure 10.

It is important to recognize that $K_{l}^{\prime}$ determined from the shock data under controlled uniaxial strain conditions is not necessarily equivalent to the pressure derivative of the bulk modulus commonly reported in static high pressure equation-of-state studies. It is equivalent only if Poisson's ratio (or equivalently, the ratio $K / G$ ) is independent of the state of mean stress. The nonlinear longitudinal coefficients are governed by the same intermolecular force laws, however, and provide useful data for verifying high-pressure equations of state of ceramic materials.

It is worth noting that the data for $K_{l}^{\prime}$ in Figure 10, when extrapolated to the zero pressure theoretical density for silicon carbide of $3210 \mathrm{~kg} / \mathrm{m}^{3}$ yields a zero pressure value of about $K_{l o}{ }^{\prime} \cong 3.2$. This is somewhat lower than the corresponding value for the pressure dependence of the bulk modulus of $K_{l o}{ }^{\prime} \cong 3.7-4.0$ measured by Aleksandrov, et al. (1990). Ignor- 
ing possible differences due to the comparison of dynamic and static data, this result would suggest some sensitivity of Poisson's ratio to compression.

The broader dynamic stress versus strain properties of silicon carbide during stress wave decompression can be determined from the full release profile through a method of interactive computer analysis. This method used the strain-hardening elastic-plastic model discussed in Section 4 with parameters which were adjusted through interactive stress-wave calculations until agreement with arrival and shape of the compression and release wave was achieved. The resulting stress-strain path was then accepted as the material response for that wave profile. The inferred stress-strain paths from computer simulations are compared with Hugoniot and calculated hydrodynamic behavior in Figure 4.

It is important to note the near metal-like elastic-plastic behavior of silicon carbide. The dynamic stress-strain paths in Figure 4 indicate an initial and sustained high-level of shear strength. Unloading behavior is also characteristic of elastic-plastic response.

The release curve in test CE-32 was unique in that the peak stress state achieved prior to unloading was well below (approximately 75\%) the Hugoniot elastic limit of the silicon carbide ceramic. Consequently, the release wave should represent strictly nonlinear elastic response of the material. Elastic properties have been determined by Kipp and Grady (1992) and are discussed in Section 4. This release profile also provides a spall pullback signal. A spall strength based on an acoustic approximation is calculated from the relation

$$
\sigma_{s}=\frac{1}{2}\left(\rho_{1} C_{1}+\rho_{2} C_{2}\right) \Delta u,
$$

where 1 and 2 refer to elastic properties of silicon carbide and lithium fluoride, respectively, and $\Delta u$ is the amplitude of the velocity pullback signal (see profile for CE-32 in the Appendix). A spall strength of $0.42 \mathrm{GPa}$ was calculated for silicon carbide from the test results of CE-32. Pullback signals characteristic of dynamic tension and spall were not observed in the three tests in which the Hugoniot elastic limit was exceeded during initial shock compression. It can be speculated that pervasive microcracking during inelastic deformation in the compression shock process seriously degraded the cohesive properties of the ceramic.

Finally, test CE-42 was performed in which the layered-material impactor led to a history of cyclic loading in which the silicon-carbide ceramic was first shock compressed to approximately $30 \mathrm{GPa}$ (nearly identical to test CE-4) and then decompressed to about onehalf of the Hugoniot stress. This decompression is a backward-facing release wave originating at the lithium-fluoride-window interface and, consequently, is not observed in the interface velocity profile shown in Figure 11. A tantalum plate behind the lithium fluoride in the layered impactor leads to recompression and a subsequent second decompression of the silicon carbide. The elastic-plastic character on recompression is observed in the second wave in Figure 11 at about 1.5-1.6 $\mu \mathrm{s}$. This experiment provides a stringent test for computational material response models in terms of cyclic shear-strength behavior. 


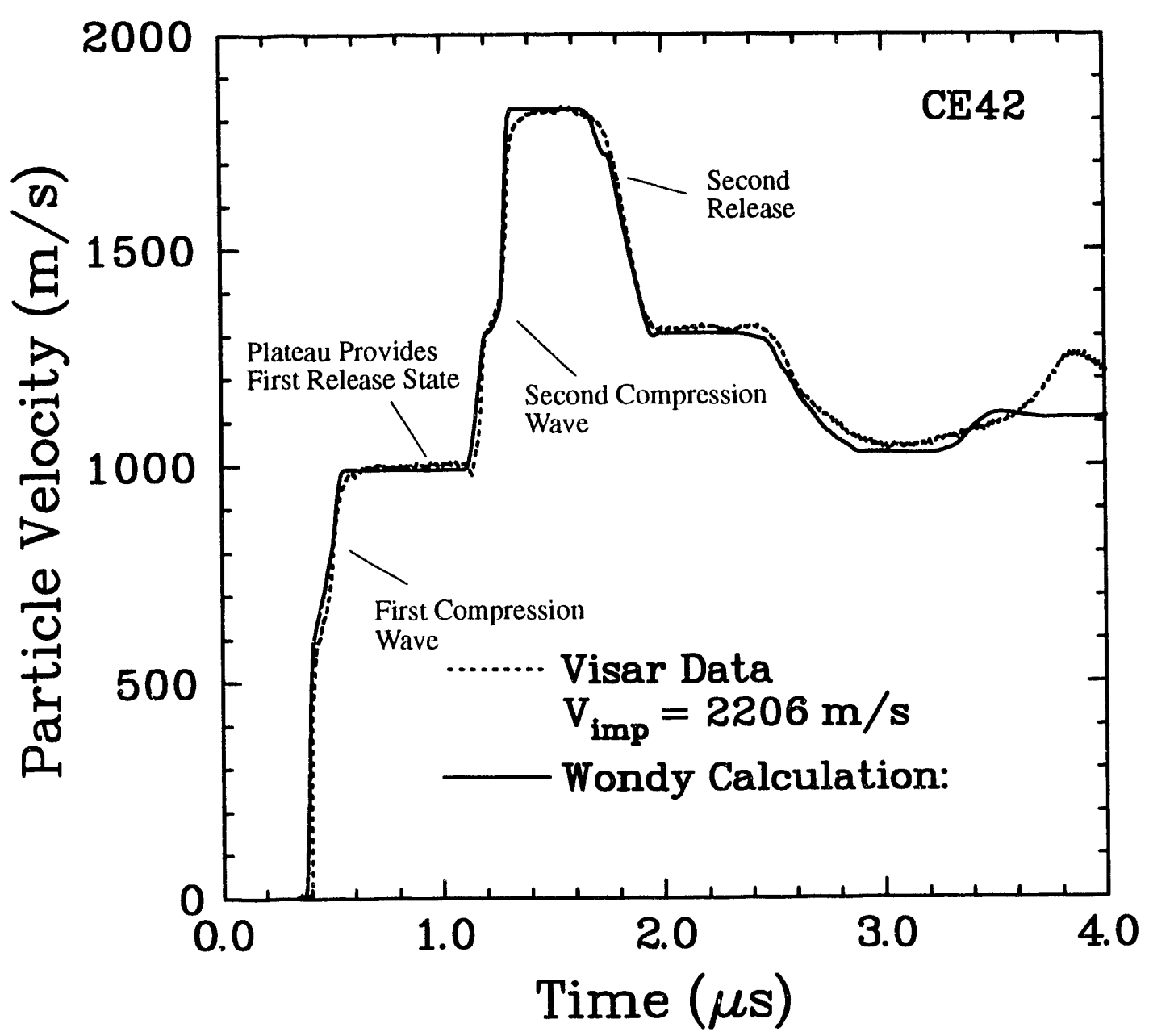

Figure 11. Multiple shock compression and release experiment and calculation in silicon carbide.

A WONDY calculation of experiment CE-42 was made using the strain-hardening elasticplastic parameters for the silicon carbide and the ancillary material parameters listed in Table 3. The comparison is shown in Figure 11 in which excellent agreement is observed for nearly all of the wave structure features between calculation and experiment. The exceptions are the absence of the slight down turn at the end of the first shock, the dispersed wave structure at the top of the second shock, and the exaggerated release in the tantalum at the end of the second shock.

In all other respects, the timing of waves and the breaks for yielding within the profile are reproduced quite accurately by the calculation. For this silicon carbide, the strain-hardening elastic-plastic model is able to represent the material response over a wide range of shock load and release under conditions of uniaxial strain deformation. 
Shock Compression Properties of Silicon Carbide

(Intentionally Left Blank) 


\section{Conclusions}

From the shock response characteristics of silicon carbide measured in the present investigation, the material appears to be very metal-like in its dynamic shear properties. Although the dynamic shear strength of silicon carbide ceramic is an order of magnitude higher than some of the strongest metals, its hardening characteristics during shock compression, and its elastic-plastic-like behavior upon deformation reversal during shock release, are very similar to the behavior of a number of metals. A work-hardening elasticplastic model was quite adequate for numerical simulation of the measured wave-profile data. The same cannot be said for other ceramics which have been tested [Kipp and Grady, 1989].

The present analysis indicates a hardening of the shear strength of silicon carbide during post-yield deformation by as much as 30 to 50 percent above the initial yield value at the Hugoniot elastic limit. This calculation is based on the offset between the measured Hugoniot data and a calculated hydrodynamic curve. Diamond-anvil measurements by Bassett and Weathers [Holmquist, 1991$]$ indicate somewhat stiffer hydrostatic behavior for silicon carbide. Recent hydrodynamic shock-compression experiments on silicon carbide and metal mixtures, however, indicate a compressibility for silicon carbide closer to the calculated extrapolation of ultrasonic data [Grady, 19921. Thus, although some degree of postshock hardening appears to be appropriate for silicon carbide, more detailed statements will have to wait until the hydrodynamic response issue is resolved.

An extensive study of the spall strength of silicon carbide has not yet been performed. However, in one experiment in which shock compression to about $75 \%$ of the Hugoniot elastic limit was achieved, a spall strength of about $0.4 \mathrm{GPa}$ was estab;ished for the material-comparable with other high-strength ceramics $\left(\mathrm{Al}_{2} \mathrm{O}_{3}, \mathrm{~B}_{4} \mathrm{C}, \mathrm{TiB} 2, \mathrm{AIN}\right)$. Further, the shape of the spall signal and the low value of impulse coupled into the spalled segment suggested a very brittle dynamic fracture process. Experiments performed at shock stresses above the Hugoniot elastic limit show negligible spall strength - consistent with loss of material cohesion during compressive shock deformation. These observations are sinilar to those of Munson and Lawrence (1979) on aluminum oxide ceramic in which they attributed loss of tensile strength to pervasive microcracking during shock compression. Similar mechanisms appear to govern deformation in silicon carbide.

Gust, et al. (1973) have suggested a shock-induced phase change in silicon carbide at about $24 \mathrm{GPa}$ from shock-compression data. The present shock-wave data do not provide clear evidence for a phase transition within the 0 to $50 \mathrm{GPa}$ shock-pressure range of the study. Examination of silicon carbide samples shocked to as high as $80 \mathrm{GPa}$ /Kovtun and Timofeeva, 1988] did not reveal quenched high-pressure phases. Also, the static compression study of Bassett and Weathers [Holmquist, 1991] on silicon carbide does not provide evidence for a high-pressure transition in static high-pressure measurements. 
(Intentionally Left Blank) 


\section{References}

1. Aleksandrov, I.V., A. F. Goncharov, E. V. Jakovenko and S. M. Stishov, High Pressure Research - XII AIRAPT Conference, Gordon and Breach Science Pub., pp. 938940, 1990.

2. Barker, L. M. and R. E. Hollenbach, J. Appl. Phys., 43, 4669, 1972.

3. Barker, L. M. and E. G. Young, Sandia National Laboratories Report SLA-74-0009, June 1994.

4. Chen, P. J., (private communication), 1991.

5. Chhabildas, L. C. and A. L. Ruoff, J. Appl. Phys., 47, 4182-4187, 1976.

6. Grady, D. E., Proceedings of the XIII International AIRAPT Conference, Bangalore, India, October 7-11, 1991 (in press).

7. Grady, D. E., Sandia National Laboratories Technical Memorandum (unpublished), June, 1992.

8. Gust, W. H., A. C. Holt, and E. B. Royce, J. Appl. Phys., 44, 550, 1973.

9. Holmquist, T. J., Alliant Techsystem Report, October 1991.

10. Kipp, M. E. and R. J. Lawrence, Sandia National Laboratories Technical Report SAND81-0930, June 1982.

11. Kipp, M. E. and D. E. Grady, Sandia National Laboratories Technical Report SAND89-1461, July 1989.

12. Kipp, M. E. and D. E. Grady, Shock Waves in Condensed Matter - 1991,

S. C. Schmidt, et al., eds., North Holland, pp. 459-462, 1992.

13. Kovtun, V. I., and I. I. Timofeeva, Sov. Powder Metall. Metal Ceram., 8/308(1988),673.

14. Jeanloz, R., J. Geophys. Res., 94, 5873-5886, 1989.

15. Munson, D. E. and R. J. Lawrence, J. Appl. Phys., 50, 6272, 1979.

16. Ruoff, A. L., and L. C. Chhabildas, High-Pressure Science and Technology - XI AIRAPT Conference, Volume 1, K. D. Timmerhaus and M. S. Barber, eds., Plenum Press, pp. 19-32, 1979.

17. Steinberg, D. J., Lawrence Livermore National Laboratory Technical Report UCRLID-106004, September, 1990. 
Shock Compression Properties of Silicon Carbide

18. Wise, J. L. and L. C. Chhabildas, Shock Waves in Condensed Matter - 1985, edited by Y. M. Gupta (Plenum, 1986) p. 441. 


\section{APPENDIX A}

\section{Interface wave-profile data}

The present appendix is comprised of the primary data sheet for each experimental test including initial material properties, geometry parameters, and the VISAR velocity profile. 
TEST NUMBER: CE 4.

TEST PURPOSE: Shock and release equation of state on silicon carbide

TARGET MATERIAL SPECIFICS: Silicon carbide. Density $=3177 \mathrm{~kg} / \mathrm{m} 3$. $\mathrm{CL}=12.06 \mathrm{~km} / \mathrm{s}$. CS $=7.67 \mathrm{~km} / \mathrm{s}$. Sample $($ disc) thickness $=8.939 \mathrm{~mm}$. Sample diameter $=55.0 \mathrm{~mm}$.

PROJECTILE MATERIAL SPECIFICS: Symmetric impact (SiC-on-SiC). Sample (disc) thickness $=3.987 \mathrm{~mm}$. Sample diameter $=55.0 \mathrm{~mm}$. Impactor backing $=$ polyurathane foam -- density $=320 \mathrm{~kg} / \mathrm{m} 3$-- thickness $=6 \mathrm{~mm}$.

WINDOW MATERIAL SPECIFICS: Lithium fluoride (cylinder). length $=25.4 \mathrm{~mm}$.

Diameter $=50.8 \mathrm{~mm}$.

IMPACT VELOCITY: $1.542 \mathrm{~km} / \mathrm{s}$.

IMPACT TIMING: First wave arrival corresponds to ultrasonic longitudinal transit time through sample.

COMMENTS: Samples were produced by Eagle Picher Industries and provided by Los Alamos National Laboratories.

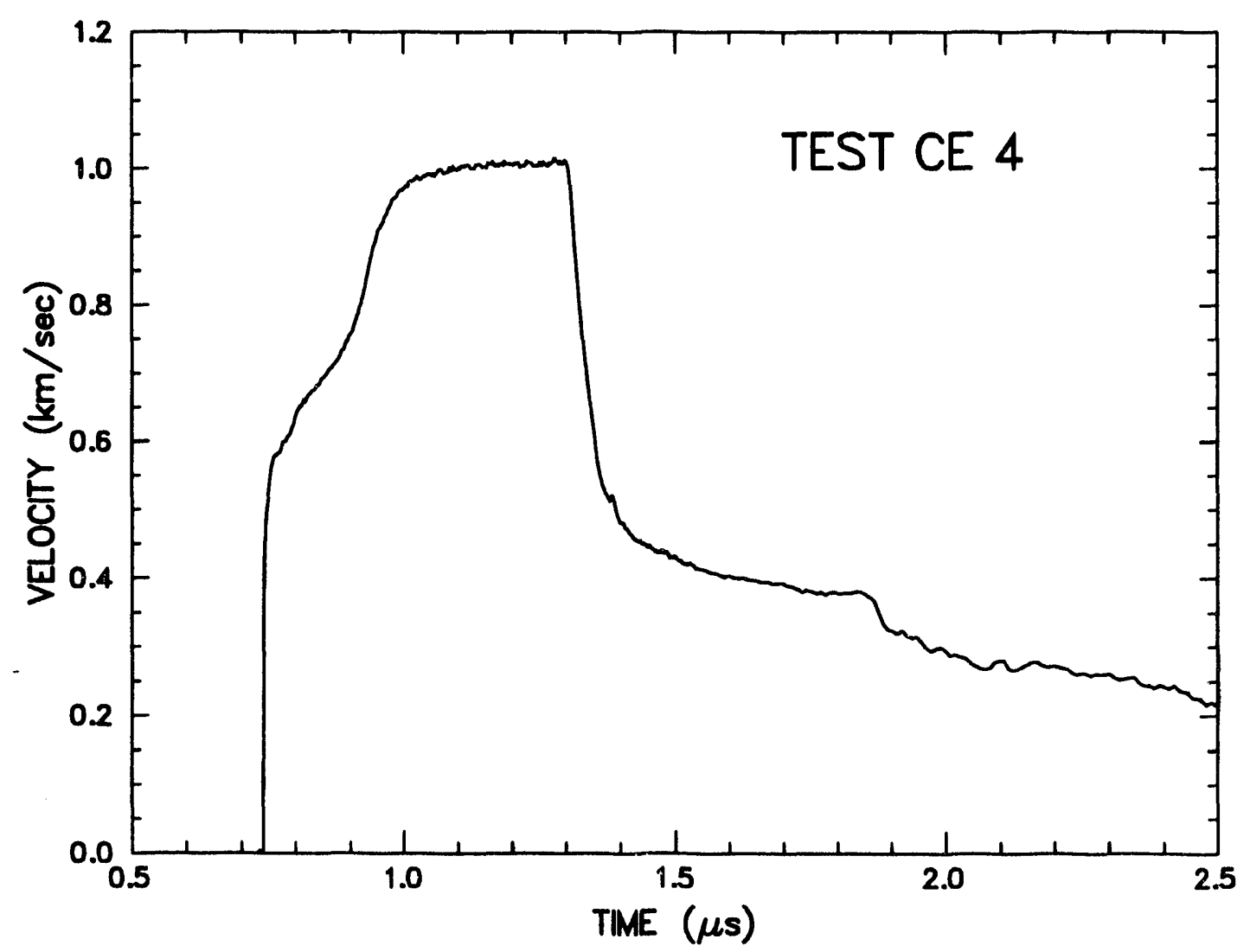


TEST NUMBER: CE 5 .

TEST PURPOSE: SF ock and release equation of state on silicon carbide

TARGET MATEIIAL SPECIFICS: Silicon carbide. Density $=3177 \mathrm{~kg} / \mathrm{m} 3$. $\mathrm{CL}=12.06 \mathrm{~km} / \mathrm{s}$. CS $=7.67 \mathrm{~km} / \mathrm{s}$. Sample (disc) thickness $=8.940 \mathrm{~mm}$. Sample diameter $=55.0 \mathrm{~mm}$.

PROJECTILE MATERIAL SPECIFICS: Symmetric impact (SiC-on-SiC).Sample (disc) thickness $=3.995 \mathrm{~mm}$. Sample diameter $=55.0 \mathrm{~mm}$. Impactor backing $=$ polyurathane foam -- density $=640 \mathrm{~kg} / \mathrm{m} 3$-- thickness $=6 \mathrm{~mm}$.

WINDOW MATERIAL SPECIFICS: Lithium fluoride (cylinder). length $=25.4 \mathrm{~mm}$. Diameter $=50.8 \mathrm{~mm}$.

IMPACT VELOCITY: $2.100 \mathrm{~km} / \mathrm{s}$.

IMPACT TIMING: First wave arrival corresponds to ultrasonic longitudinal transit time through sample.

COMMENTS: Samples were produced by Eagle Picher Industries and provided by Los Alamos National Laboratories.

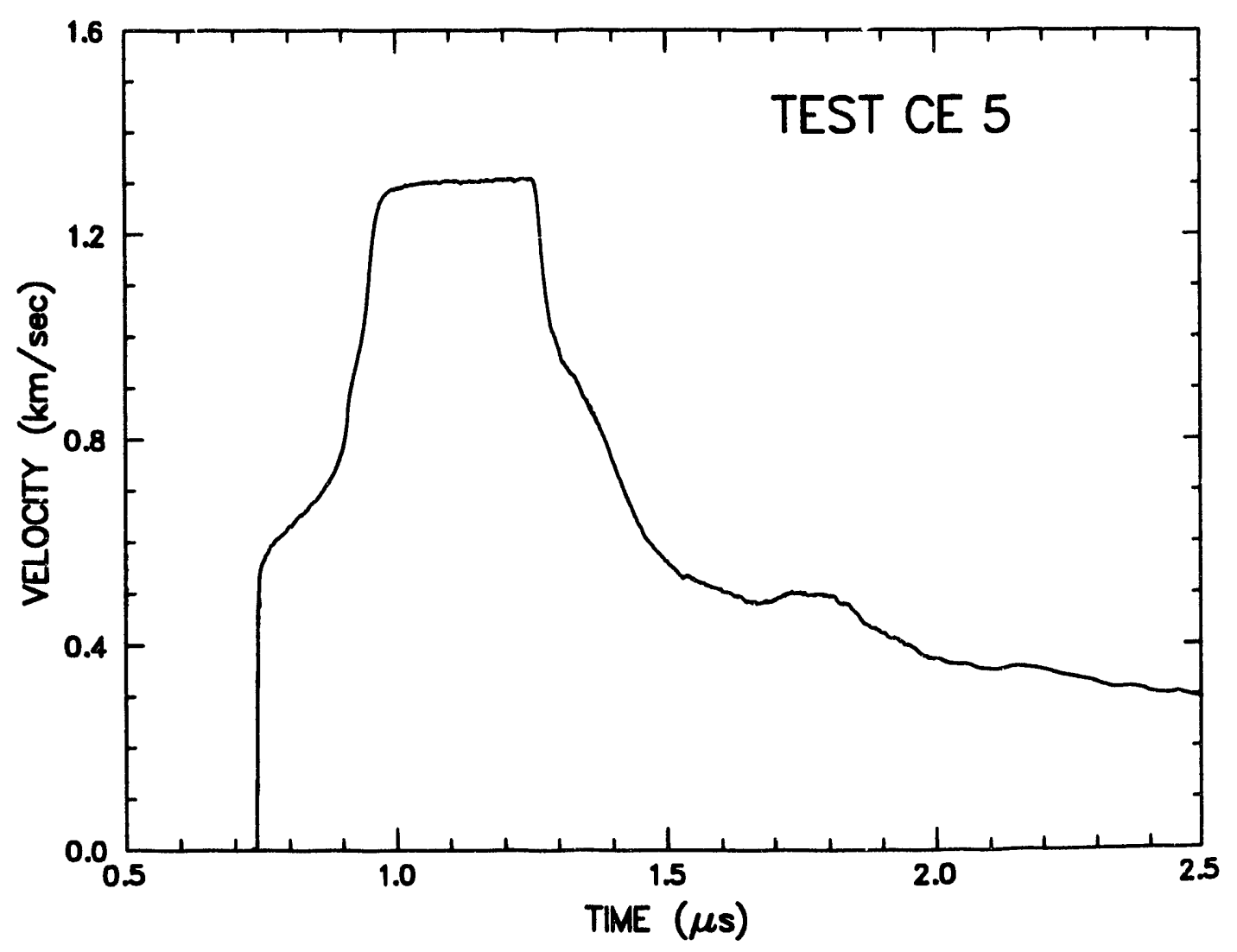


TEST NUMBER: CE 31.

TEST PURPOSE: Shock and release equation of state on silicon carbide

TARGE'T MATERIAL SPECIFICS: Silicon carbide. Density $=3177 \mathrm{~kg} / \mathrm{m} 3$.

$\mathrm{CL}=12.06 \mathrm{~km} / \mathrm{s} . \mathrm{CS}=7.67 \mathrm{~km} / \mathrm{s}$. Sample (disc) thickness $=8.956 \mathrm{~mm}$. Sample diameter $=52.5 \mathrm{~m} \cdot \mathrm{m}$.

PROJECTILE MATERIAL SPECIFICS: Tantalum impactor. Sample (disc)

thickness $=1.5 .5 \mathrm{~mm}$. Sample diameter $=87.5 \mathrm{~mm}$. Impactor backing $=$ polyurathane foam -- density $=640 \mathrm{~kg} / \mathrm{m} 3$-- thickness $=6 \mathrm{~mm}$.

WINDOW MATERIAL SPECIFICS: Lithium fluoride (cylinder). length $=25.4 \mathrm{~mm}$.

Diame $^{*}$. $=50.8 \mathrm{~mm}$.

IMPACT VEL_OCITY: $2.118 \mathrm{~km} / \mathrm{s}$.

IMPACT TIMING: First wave arrival corresponds to ultrasonic longitudinal transit time through sample.

COMMENTS: Samples were produced by Eagle Picher Industries and provided by Los Alamos National Laboratories.

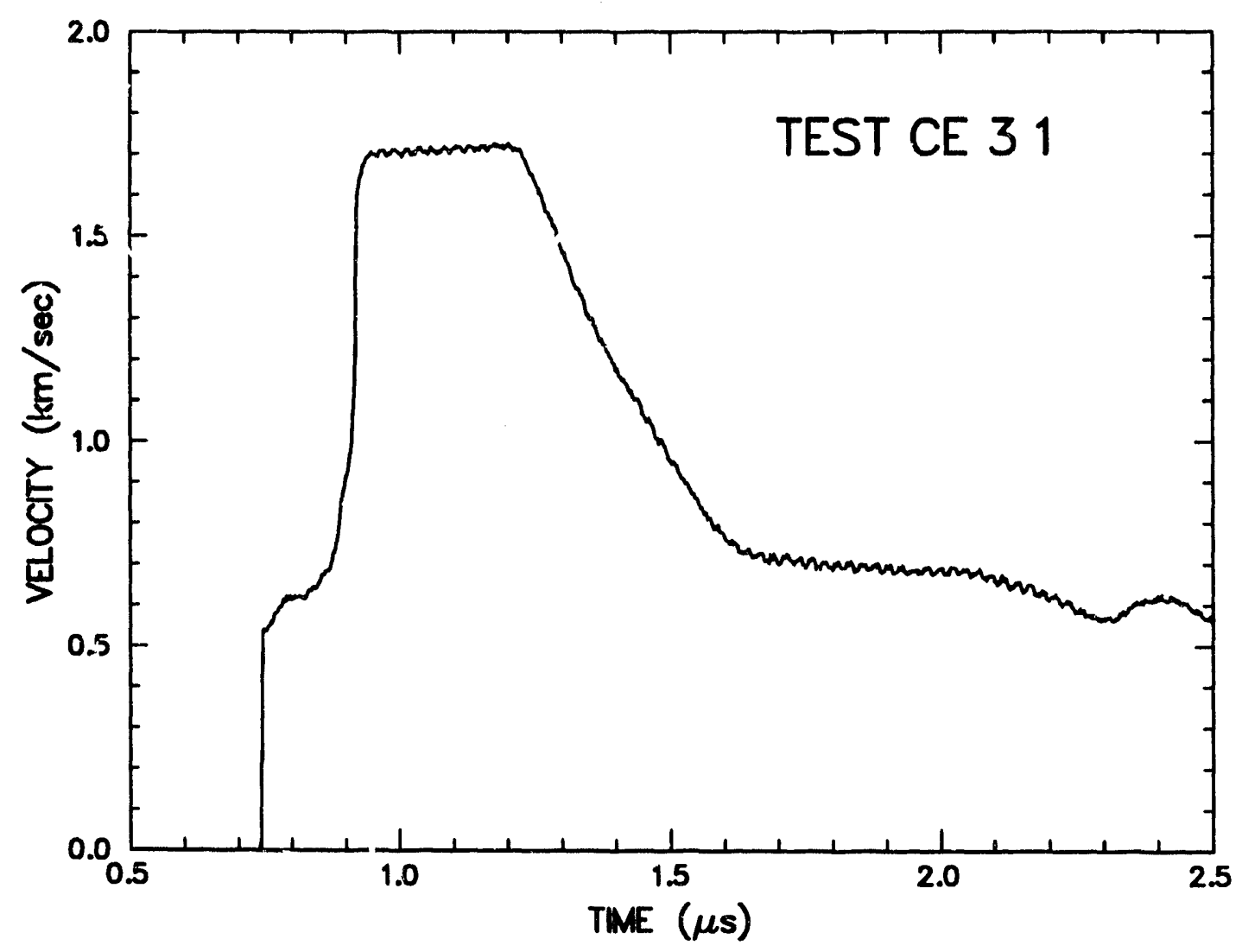


TEST NUMBER: CE 32.

TEST PURPOSE: Elastic nonlinearity and spall on silicon carbide

TARGET MATERIAL SPECIFICS: Silicon carbide. Density $=3177 \mathrm{~kg} / \mathrm{m} 3$.

$\mathrm{CL}=12.06 \mathrm{~km} / \mathrm{s}$. CS $=7.67 \mathrm{~km} / \mathrm{s}$. Sample (disc) thickness $=9.841 \mathrm{~mm}$. Sample diameter $=50.0 \mathrm{~mm}$.

PROJECTILE MATERIAL SPECIFICS: Symmetric impact ( $\mathrm{Si}$ ¿-on-SiC). Sample (disc) thickness $=4.958 \mathrm{~mm}$. Sample diameter $=50.0 \mathrm{~mm}$. Impact $\mathrm{r}$ backing $=$ polyurathane foam -- density $=320 \mathrm{~kg} / \mathrm{m} 3$-- thickness $=6 \mathrm{~mm}$.

WINDOW MATERIAL SPECIFICS: Lithium fluoride (cylinde $r$ ). length $=25.4 \mathrm{~mm}$.

Diameter $=50.8 \mathrm{~mm}$.

IMPACT VELOCITY: $0.612 \mathrm{~km} / \mathrm{s}$.

IMPACT TIMING: First wave arrival corresponds to ultrasonic longitudinal transit time through sample.

COMMENTS: Samples were produced by Eagle Picher Industries and provided by Los Alamos National Laboratories.

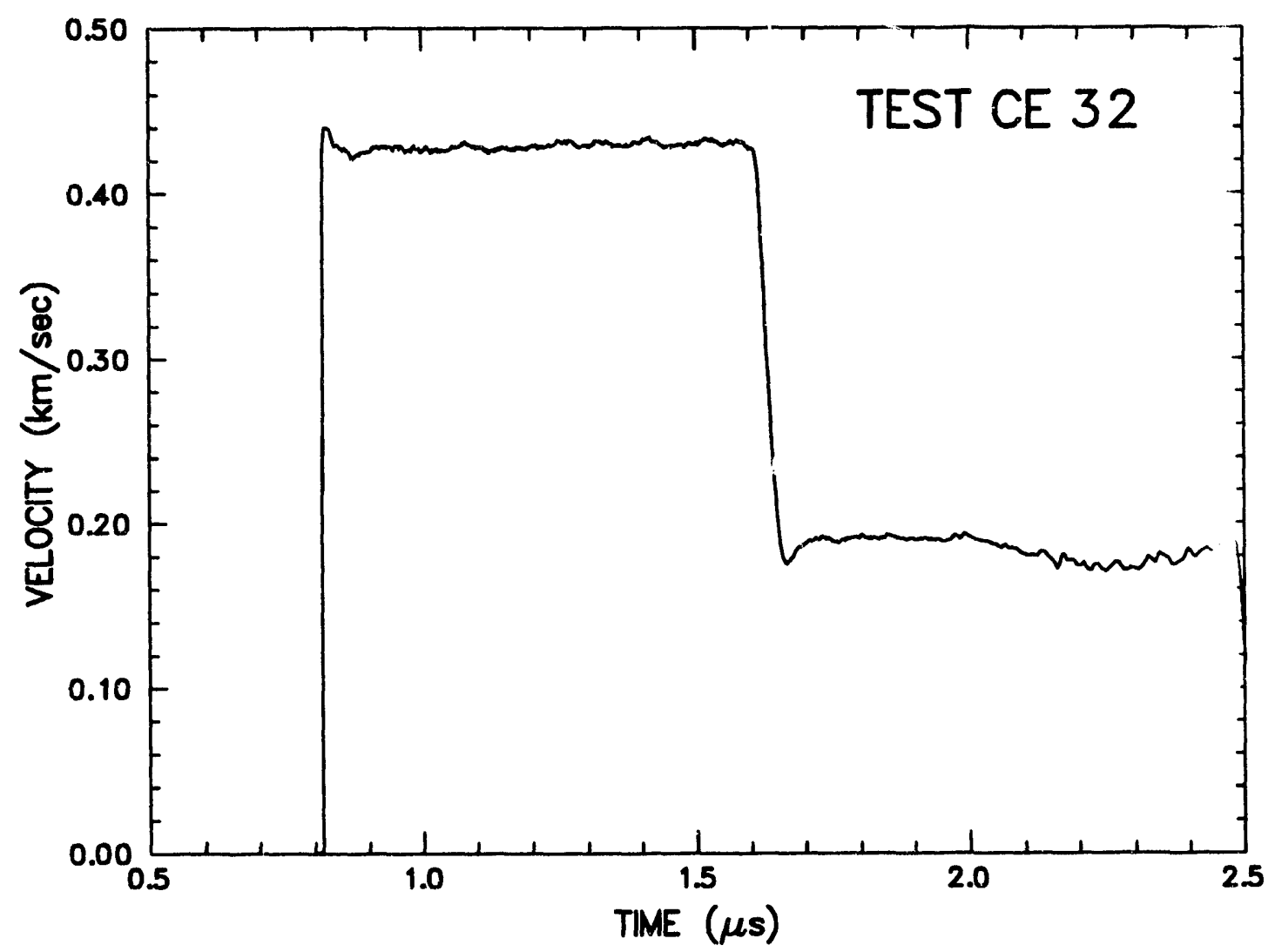


Shock Compression Properties of Silicon Carbide

TEST NUMBER: CE 42.

TEST PURPOSE: Multiple shock and release equation of state of silicon carbide.

TARGET MATERIAL SPECIFICS: Silicon carbide. Density $=3177 \mathrm{~kg} / \mathrm{m} 3$.

$\mathrm{CL}=12.06 \mathrm{~km} / \mathrm{s}$. CS $=7.67 \mathrm{~km} / \mathrm{s}$. Sample (disc) thickness $=4.963 \mathrm{~mm}$.

Sample diameter $=76.14 \mathrm{~mm}$.

PROJECTILE MATERIAL SPECIFICS: Lithium fluoride impactor.

Sample (disc) thickness $=3.297 \mathrm{~mm}$. Sample diameter $=50.8 \mathrm{~mm}$.

Lithium fluoride backing $=$ tantalum. Tantalum disc thickness $=1.510 \mathrm{~mm}$ and diameter $=87.49 \mathrm{~mm}$. Tantalum disc backed by approximately $12 \mathrm{~mm}$ thickness aluminum plate.

WINDOW MATERIAL SPECIFICS: Lithium fluoride (cylinder). length $=25.4 \mathrm{~mm}$. Diameter $=50.7 \mathrm{~mm}$.

IMPACT VELOCITY: $2.206 \mathrm{~km} / \mathrm{s}$.

IMPACT TIMING: Profile is not time aligned.

COMMENTS: Samples were produced by Eagle Picher Industries and provided by Los Alamos National Laboratories.

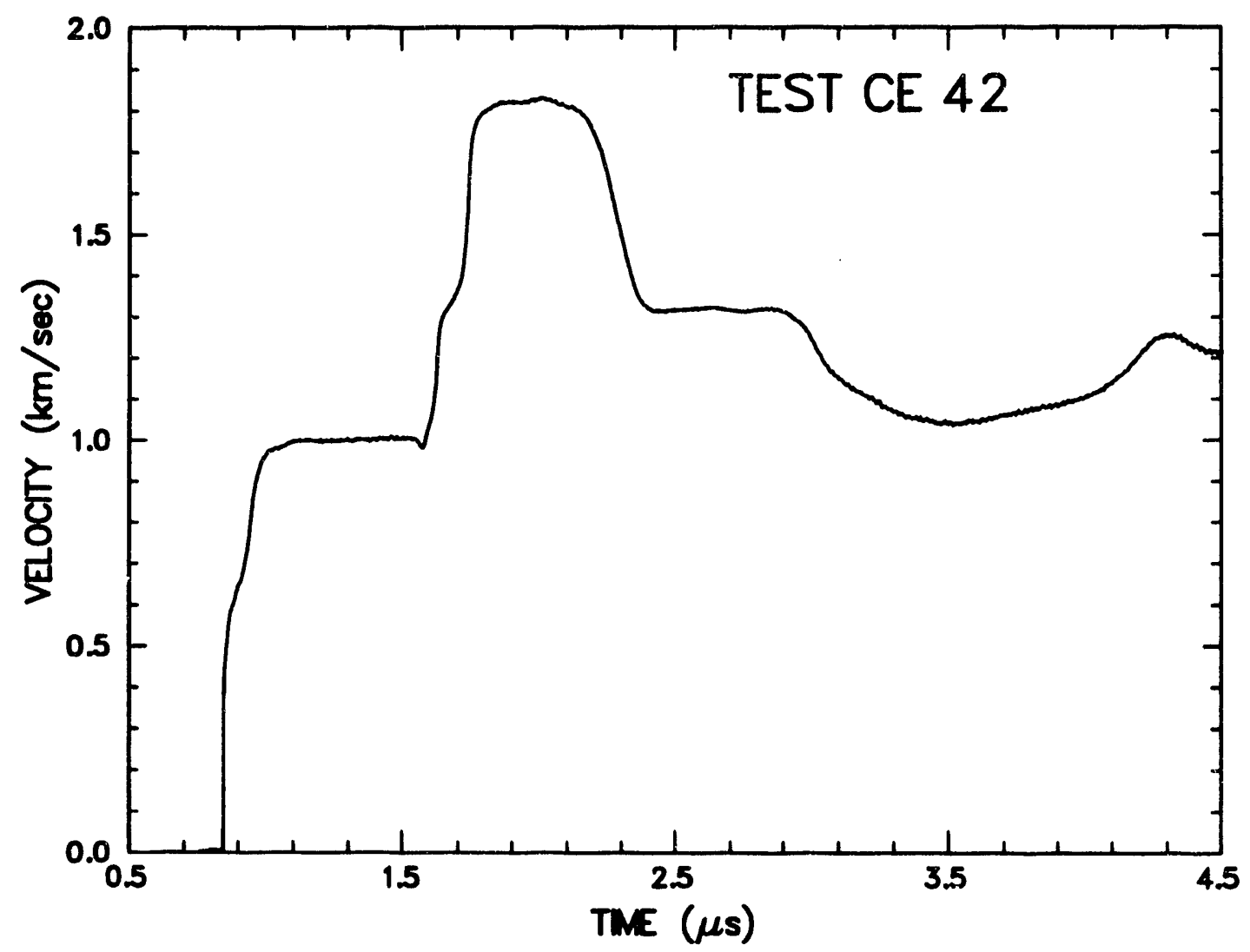




\section{DISTRIBUTION:}

INTERNAL

$\begin{array}{ll}1400 & \text { E. H. Barsis } \\ 1431 & \text { J. M. McGlaun } \\ 1431 & \text { K. G. Budge } \\ 1431 & \text { E. S. Hertel } \\ 1431 & \text { R. J. Lawrence } \\ 1431 & \text { J. S. Peery } \\ 1431 & \text { A. C. Robinson } \\ 1431 & \text { T. G. Trucano } \\ 1431 & \text { M. K. Wong } \\ 1432 & \text { P. Yarrington } \\ 1432 & \text { P. J. Chen } \\ 1432 & \text { H. E. Fang } \\ 1432 & \text { A. V. Farnsworth } \\ 1432 & \text { G. I. Kerley } \\ 1432 & \text { M. E. Kipp (15) } \\ 1432 & \text { S. A. Silling } \\ 1432 & \text { P. A. Taylor } \\ 1433 & \text { P. L. Stanton } \\ 1433 & \text { J. A. Ang } \\ 1433 & \text { L. C. Chhabildas } \\ 1433 & \text { D. A. Crawford } \\ 1433 & \text { M. D. Furnish } \\ 1433 & \text { D. E. Grady (25) } \\ 1500 & \text { D. J. McCloskey } \\ 1511 & \text { J. S. Rottler } \\ 1512 & \text { A. C. Ratzel } \\ 1561 & \text { H. S. Morgan } \\ 1562 & \text { R. K. Thomas } \\ 1562 & \text { J. W. Swegle } \\ 2565 & \text { S. T. Montgomery } 1433 \\ 6111 & \text { J. L. Wise } \\ 7141 & \text { Technical Library (5) } \\ 7151 & \text { Technical Publications } \\ 7613 & \text { Document Processing for } \\ & \text { DOE/OSTI (2) } \\ 8523-2 \text { Central Technical Files } \\ 9722 & \text { W. Tucker } \\ 9723 & \text { M. J. Forrestal } \\ 9723 & \text { V. K. Luk } \\ & \end{array}$

\section{EXTERNAL}

T. F. Adams

Los Alamos National Laboratory MS F663

Los Alamos, NM 87545

T. J. Ahrens

Geophysics Division MS/252-21

California Institute of Technology

Pasadena, CA 91125

F. Allahdadi

Phillips Laboratory

PL/WSSD

Kirtland AFB, NM 87117-6008

M. L. Alme

102 Stevens Forrest Professional Center

9650 Santiago Road

Columbia, MD 21045

C. E. Anderson

Southwest Research Institute

6220 Culebra Road

San Antonio, TX 78284

D. W. Baum

Lawrence Livermore National Laboratory

Livermore,CA 94550

S. J. Bless

Institute for Advanced Technology

4030-2 W. Braker Lane

Austin, TX 78759-5329

W. Blumenthal

Los Alamos National Laboratory

MS E546

Los Alamos, NM 87545 
S. Brar

Impact Physics Laboratory

University of Dayton Research Institute

300 College Park

Dayton, OH 45469-3546

W. J. Bruchey

U.S. Army Research Laboratory

SLCBR-TB-A

Aberdeen Proving Ground, MD 21005-

5066

M. Burkett

Los Alamos National Laboratory

MS J576

Los Alamos, NM 87545

A. Charters

General Research Corporation

5383 Hollister Avenue

Santa Barbara, CA 93160-6770

S. Chou

Army Research Laboratory

Materials Directorate

AMSRL-MA-DA

Watertown, MA 02172-0001

R. Clifton

Brown University

Division of Engineering

Providence, RI 02912

J. A. Collins

US Air Force Armament Laboratory

AD/MNW

Eglin Air Force Base, FL 32542-5434

J. W. Coltman

Simula Inc.

10016 South 51st Street

Phoenix, AZ 85044
E. Cort

Los Alamos National Laboratory

MS K574

Los Alamos, NM 87545

D. Curran

SRI International

333 Ravenswood Avenue

Menlo Park, CA 94025

D. Dandekar

U.S. Army Research Laboratory

Materials Directorate

AMSRL-MA-DA

Watertown, MA 02172-0001

K. Epstein

DOW Chemical USA

Ordnance Systems, 800 Building

Midland, MI 48667

P. Follansbee

Los Alamos National Laboratory

MS K663

Los Alamos, NM 87545

J. C. Foster, Jr.

US Air Force Armament Laboratory

AD/MNW

Eglin Air Force Base, FL 32542-5434

J. R. Furlong

SAIC

1710 Goodridge Dr.

McLean VA 22102

Y. Gupta

Washington State University

Department of Physics

Pullman, WA 99163

G. Hauver

U.S. Army Research Laboratory

AMSRL-WT-TA

Aberdeen Proving Ground, MD 21005-

5066 


\section{T. Holmquist}

Alliant Techsystems, Inc.

7225 Northland Drive

Brooklyn Park, MN 55428

Y. Horie

North Carolina State University

Dept. of Civil Engineering

Raleigh, NC 27607

K. Iyer

US Army Research Office

P. O. Box 12211

Research Triangle Park, NC 27709

G. Johnson

Alliant Techsystems, Inc.

7225 Northland Drive

Brooklyn Park, MN 55428

J. N. Johnson

Los Alamos National Laboratory

MS B221

Los Alamos, NM 87545

K. Kimsey

U.S. Army Research Laboratory

Attn: SLCBR-TB-P

Aberdeen Proving Ground, MD 210055066

R. W. Kocher

Defense Advanced Research Projects

Agency

Land Systems Office

3701 North Fairfax Drive

Arlington, VA 22203-1714

\section{J. Lankford}

Southwest Research Institute

6220 Culebra Road

San Antonio, TX 78284
K. T. Leighton

Lanxide Armor Products, Inc.

1300 Marrows Road

P. O. Box 6077

Newark, DE 19714-6077

D. Mandell

Los Alamos National Laboratory

MS F663

Los Alamos, NM 87545

M. Manghnani

Mineral Physics Group

University of Hawaii

2525 Correa Rd.

Honolulu, HA 96822

P. Maudlin

Los Alamos National Laboratory

MS K557

Los Alamos, NM 87545

H. C. Meyer

U.S. Army Research Laboratory

AMSRL-WT-TA

Aberdeen Proving Ground, MD 21005-

5066

M. Meyer

Univ. of Calif. at San Diego

Dept. of Applied Mech. \& Eng. Sciences

La Jolla, CA 92093

J. D. Morrow

FMC Corporation

Ground Systems Division

1107 Coleman Avenue Box 367

San Jose, CA 95103

S. Nemat-Nasser

Univ. of Calif. at San Diego

Dept. of Applied Mech. \& Eng. Sciences

La Jolla, CA 92093 
T. Nicholas

Air Force Wright Aeronautical Labs.

Air Force Systems Command

Materials Laboratory

Wright-Patterson AFB, OH 45433

D. Orphal

California Research and Technology, Inc.

5117 Johnson Drive

Pleasanton, CA 94566

R. Palicka

CERCOM, Inc.

1960 Watson Way

P. O. Box 70

Vista, CA 92083

R. Paricio

Coors Ceramics Company

600 Ninth Street

Golden, CO 80401

W. W. Predebon

College ofEngineering

Michigan Technological University

Houghton, MI 49931

G. F. Raiser

Washington State University

Department of Physics

Pullman, WA 99163

A. M. Rajendran

Army Research Laboratory

Materials Directorate

AMSRL-MA-DA

Watertown, MA 02172-0001

G. Randers-Pehrson

US Army Ballistic Research Laboratory

SLCBR-TB-W

Aberdeen Proving Ground, MD 210055066
M. Scheidler

U.S. Army Research Laboratory

AMSRL-WT-TD

Aberdeen Proving Ground, MD 21005-

5066

P. N. Schneidewind

California Research and Technology, Inc.

5117 Johnson Drive

Pleasanton, CA 94566

S. Segletes

U.S. Army Research Laboratory

SLCBR-TB-W

Aberdeen Proving Ground, MD 21005 -

5066

D. A. Shockey

Poulter Laboratory

SRI International

333 Ravenswood Avenue

Menlo Park, CA 94025

R. Skaggs

Los Alamos National Laboratory

MS K574

Los Alamos, NM 87545

M. Slavin

U.S. Army Research Laboratory

SLCMT-MCC

Arsenal Street

Watertown, MA 02172-0001

J. M. Staehler

College of Engineering

Michigan Technological University

Houghton, MI 49931

D. Steinberg, MS L35

Lawrence Livermore National Laboratory

P. O. Box 808 
J. Sternberg

Naval Postgraduate School

Superintendent Code 412B

Monterey, CA 93943

D. J. Viechniki

U.S. Army Research Laboratory

SLCMT-MCC

Arsenal Street

Watertown, MA 02172-0001

T. Wright

U.S. Army Research Laboratory

SLCBR-TB-W

Aberdeen Proving Ground, MD 21005-

5066 

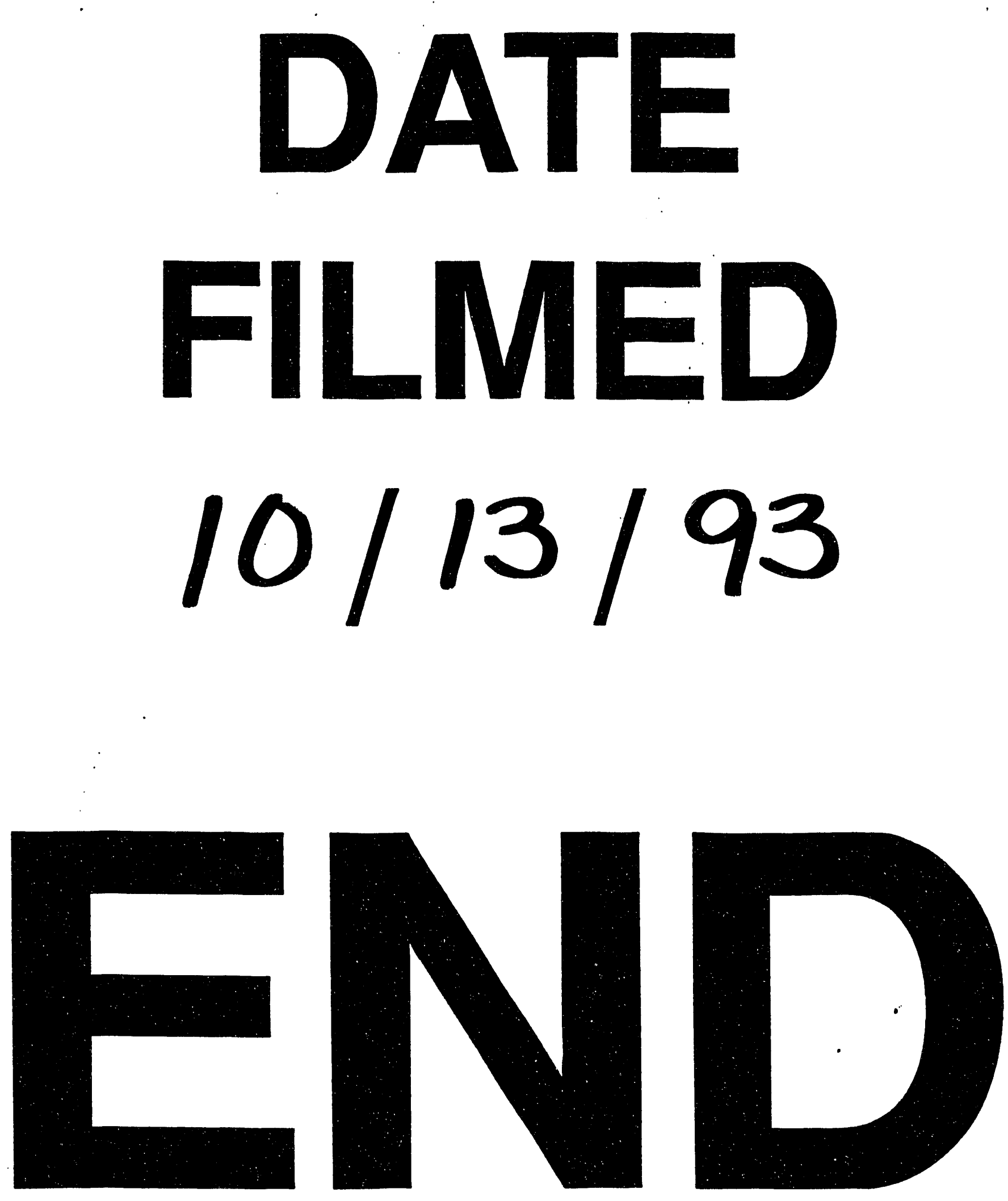
